\title{
Gauging the stakeholders' perspective: towards PPP in building sectors and housing
}

\author{
Ritika Batra ${ }^{1,2}$
}

Received: 18 April 2019 / Accepted: 21 May 2020 / Published online: 18 June 2020

(c) The Author(s) 2020

\begin{abstract}
While Public-Private Partnership (PPP) is widely adopted across various sectors, it raises a question on its meagre utilisation in the housing sector. This paper, therefore, gauges the perspective of the stakeholders in the building industry towards the application of PPP in various building sectors together with housing. It assesses the performance reliability of PPP for housing by learning possible take-aways from other sectors. The role of key stakeholders in the industry becomes highly responsible for an informed understanding and decision-making. To this end, a two-tier investigation was conducted including surveys and expert interviews, with several stakeholders in the PPP industry in Europe, involving the public sector, private sector, consultants, as well as other community/user representatives. The survey results demonstrated the success rate with PPPs, major factors important for PPPs such as profitability or end-user acceptability, the prevalent practices and trends in the PPP world, and the majority of support expressed in favour of the suitability of PPP for housing. The interviews added more detailed dimensions to the understanding of the PPP industry, its functioning and enabling the formation of a comprehensive outlook. The results present the perspective, approaches, and experiences of stakeholders over PPP practices, current trends and scenarios and their take on PPP in housing. It shall aid in understanding the challenges prevalent in the PPP approach for implementation in housing and enable the policymakers and industry stakeholders to make provisions for higher uptake to accelerate housing provision.
\end{abstract}

Keywords Public-Private Partnerships $\cdot$ Housing $\cdot$ Stakeholders $\cdot$ Public sector $\cdot$ Private sector

Ritika Batra

ar.ritikab@gmail.com

1 Chair of Architecture and Building Process, Institute of Technology in Architecture, Department of Architecture, ETH Zürich, Zürich, Switzerland

2 Bauhaus-Universität Weimar, Weimar, Germany 


\section{Introduction}

Public-Private Partnerships (PPPs) are considered a form of privatisation that can be defined broadly as an arrangement between a public and a private unit, undertaking an activity jointly for several reasons such as innovation, managerial efficiency or technical knowledge (Savas 2000; US Department of Transportation, DOT 2004; Grimsey and Lewis 2005; Roehrich et al. 2014). PPPs are also defined by the European Investment Bank (EIB) (EIB 2004, 2019) as "the relationships formed between private sectors and public bodies often to introduce private sector resources and/or expertise to provide and deliver public sector assets and services". The Public-Private Infrastructure Advisory Facility (PPIAF) (World Bank 2014) provides another definition that; "a PPP involves the private sector in aspects of the provision of infrastructure assets or of new or existing infrastructure services that have traditionally been provided by the government". To sum up, a PPP is an agreement between governments/ public and private partners where the objectives of service delivery for the public sector are aligned with profit-oriented objectives of the private sector through various possible instruments (Organisation for Economic Co-operation and Development, OECD 2012; Energy Efficient Buildings Association E2BA 2013).

PPPs have emerged in a wide variety of forms across different sectors in Europe entailing unique opportunities and challenges. For example, the UK has been leading the European PPP market during 1990-2009, with over two-thirds of the number of PPP projects in Europe across all sectors (Kappeler and Nemoz 2010). Ireland also adopted PPP as early as 1998 beginning with schools' PPPs and expanding into other sectors (Sykorovà 2013). Denmark started utilising PPP in public building and construction as an opportunity to bring about improvement in the efficiency of the projects and provide innovative solutions (Bardeleben and Puggaard 2012), further taking PPP approach as an instrument to facilitate interaction among design, construction and operation stages. Many forms of PPP began to be utilised in France during the 1990s (Sykorovà 2013) in various sectors, and predominantly in transportation. Even Norway adopted the PPP approach in 1998 beginning with transportation projects (Eriksen et al. 2007).

Among all the sectors, housing is a key typology in the building sector impacting the people directly. Housing provision involves a tremendous amount of capital investment, maintenance, and operating expenditures, requiring significant budget allocation from the government or the authority responsible for housing. However, in many of the European countries such as Austria, the UK, Ireland, Denmark, Germany, France or Netherlands, the percentage of social housing declined over the last years and could not keep pace with the overall demand (Scanlon and Whitehead 2008; Eurostat 2017; PricewaterhouseCoopers, PwC and Urban Land Institute, ULI, 2019). While PPPs have been adopted in many countries as an effective instrument for delivery of social housing developments, regeneration projects, or housing with social care, such as in the UK or Ireland (The Comptroller and Auditor General, C\&AG 2010; UN-Habitat 2011), however, there is the little existence of empirical data showing any real trends with PPP in the housing sector of Europe. Limited literature (Davidson and Malloy 2009; Moskalyk 2011; UN-Habitat 2011) available over PPP in housing further highlights the prospects of exploring the adoption of PPP widely for housing provision.

It is, therefore, crucial to understand the existing scenario of PPP in different sectors for developing a foresight about PPP in housing. PPP in housing has gained minimal momentum, perhaps, often due to its perceived lack of profitability, in comparison with other sectors in different European countries (EU-28), which can be ascertained by many official 


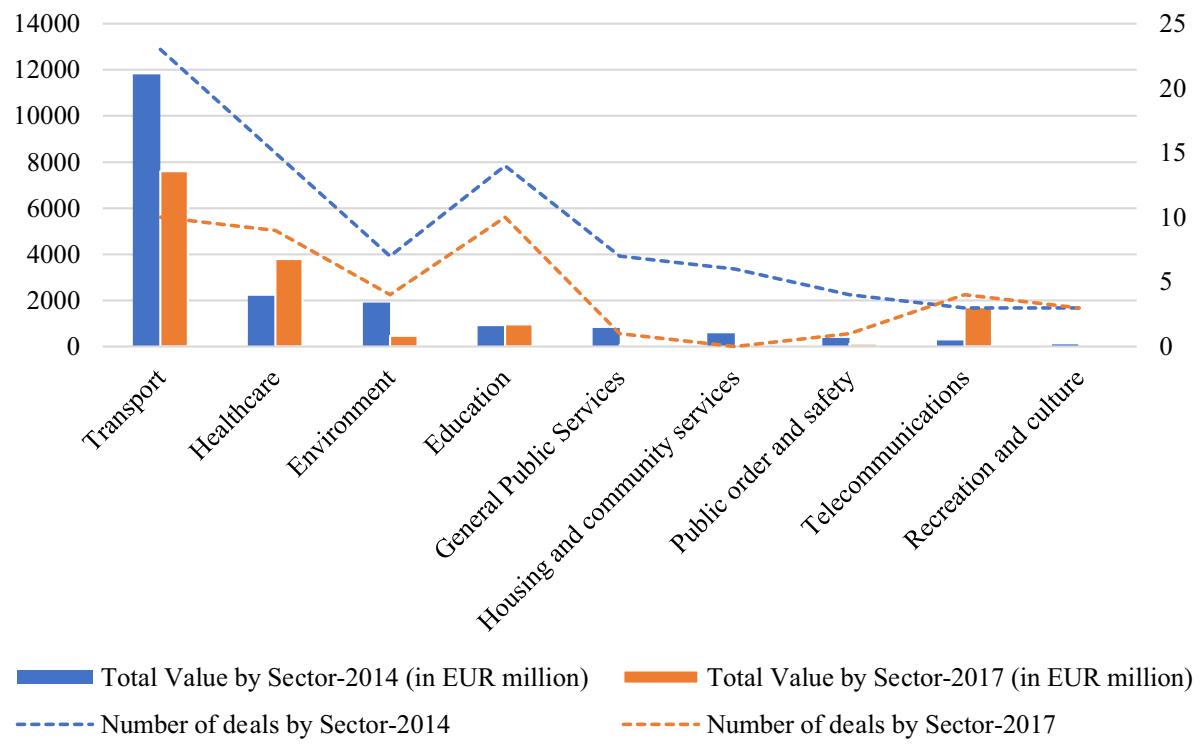

Figure 1 Scenario of PPP in housing across sectors in European PPP Market 2014 \& 2017, adapted (EPEC 2015, 2018)

reports (National Audit Office NAO 2009; C\&AG 2010; Moskalyk 2011; European PPP Expertise Centre, EPEC 2015) assessing the European (EU-28) PPP market. Even regarding the value of investment or number of deals, minimal or no application of PPP in the housing sector can be observed (see Fig. 1) (EPEC, 2015, 2016, 2017, 2018).

Also, since PPP in housing is mostly utilised in the UK (C\&AG 2010), this poses a question on the magnitude of its spread across other neighbouring countries in Europe. This is further substantiated by a study conducted by PwC (2005) highlighting the PPP activity in various countries across different sectors, demonstrating little procurements in the housing sector in countries other than the UK (see Fig. 2). Furthermore, it gives a brief overview of PPP across other sectors in seventeen EU countries, helping to frame the perspective about which countries and sectors can contribute more to housing PPPs.

The large variation in the value of investment, the number of deals, and relative overview of PPP in housing compared to other building sectors such as education or healthcare is not doing justice to fulfilling the rising housing demand in Europe (Eurostat 2017; PwC and ULI 2019). This can, therefore, help in exploring the possibility to cater to a range of housing types such as community housing, social housing or housing for the elderly (Adejumo 2008; C\&AG 2010; ACT Government 2014; URBACT 2016). The propagated benefits of PPP and its distance from the housing sector strongly acts as an inspiration to assess its feasibility and acceptability in delivering efficiency in performance in housing projects.

It is worthwhile to clarify, in line with the varied terminologies and definitions for housing, this research focuses on PPP in the entire domain of public, affordable, social or rental housing (Adejumo 2008; C\&AG 2010; URBACT 2016). There is a need to understand the different performance parameters across the sectoral spectrum and study the derivations to enable the growth of PPP in the housing sector. Therefore, this study aims at assessing, understanding and analysing the performance of a PPP approach from the perspective of 


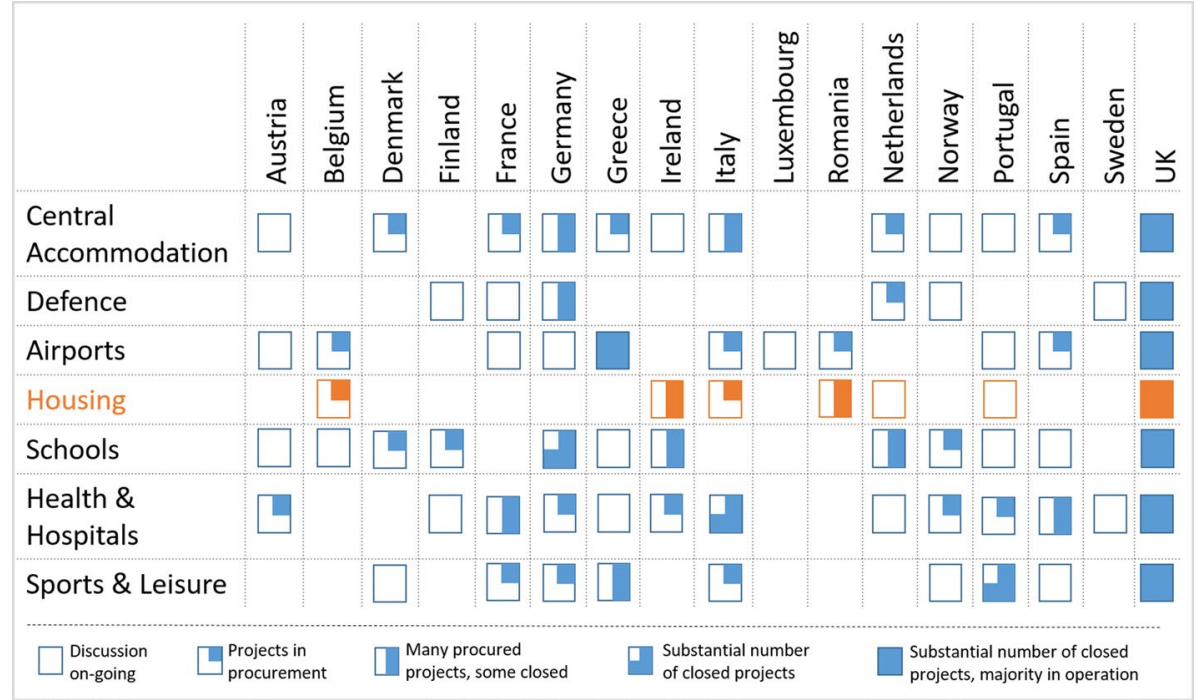

Figure 2 Relative overview of PPP in housing, adapted (PwC 2005; DOELG 2000)

stakeholders, and comprehend it for a larger question about its applicability in the housing sector. The following methodology forms the basis of this study.

\section{Methodology}

The objective of this study is to assess the outlook of the industry professionals, their attitudes and approaches towards the functioning of PPPs and their view about PPP in housing. To this end, a two-tier approach was designed comprising of surveys (40 respondents) followed by in-depth interviews (12 participants). Studies have demonstrated the use of such an approach (Davies and Osmani 2011; Gul and Menzies 2012) to generate results ensuring consistency, reliability, and validity. The structure of this approach was informed by preliminary data and information available on the PPP scenario. The surveys and interviews were structured with different foci (see Table 1) to guide through the process in a wholesome perspective.

The surveys were conducted to gain a clearer understanding of the market perspective. Its structure comprised of systematic inquiries beginning with gauging the experience and expertise of the stakeholders, progressing to understand the market scenario and inquire about their needs and requirements (refer "Appendices 1 and 2"). Each inquiry was structured with a list of plausible options based on an exhaustive literature study and preliminary surveys. The respondents comprised a range of market players from PPP, finance, policy-making and other relevant profiles in the EU as shown in Table 2.

Following the preparation of a list of contacts (based on the existing industry contacts and personal reach out) of PPP experts and practitioners, approximately 100 invitations were sent for the survey. A response rate of over $40 \%$ was received. Since it was not mandatory to answer all the inquiries, the number of respondents differ for each inquiry. Summative evaluation (Huey-Tsyh 1996) has been utilised to report the results within broad categories highlighting the experiences of the participants, the strategies adopted in PPPs 


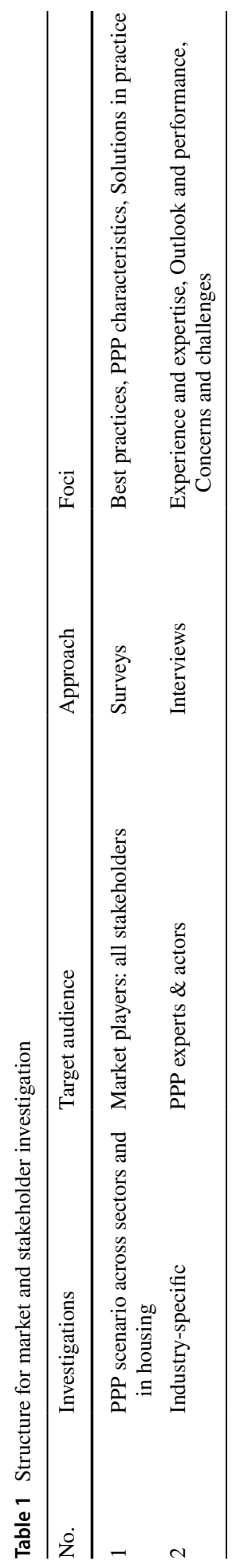




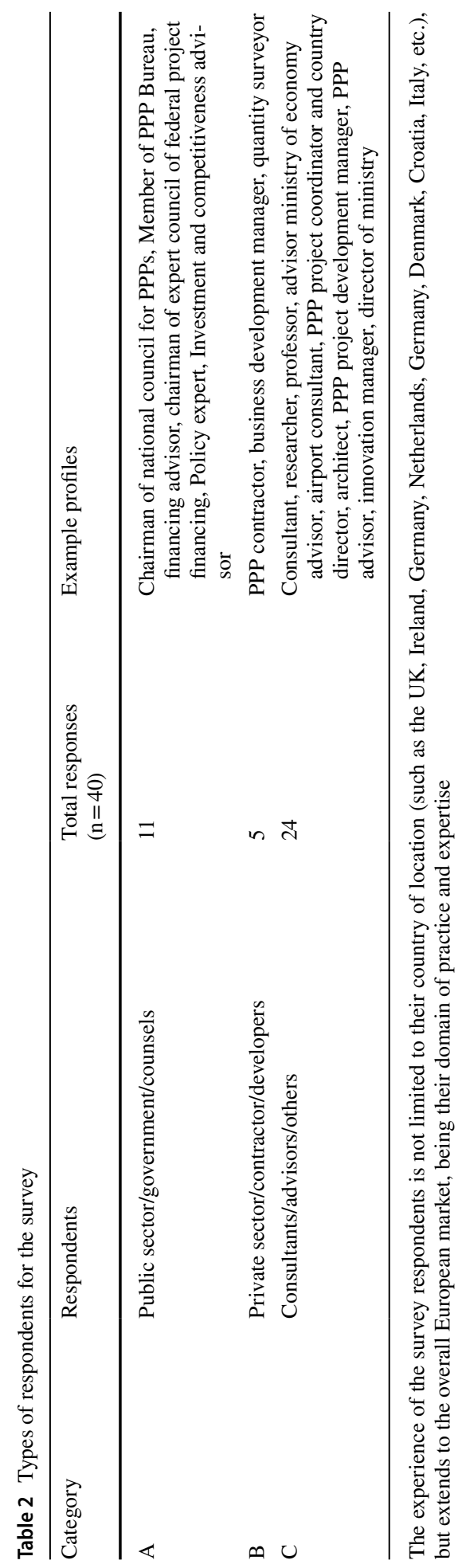


and the expectations and needs of the PPP industry (Krueger 1994). While the statistical data has been presented regarding the percentage of responses, the terms 'a few' (less than one-third of the respondents), 'some' (one-third to half), 'many' (half to two-third), and 'majority' (more than two-third) have been utilised to indicate the frequency in open inquiries that ascertain the truthfulness of the data (Meehan et al. 2000).

Following the surveys, twelve individual semi-structured interviews were organised for this study representing different backgrounds and target groups with the aim of having expert insights and gaining a comprehensive understanding (refer Appendix 1). These interviews were conducted within the EU with experienced PPP market and policy experts and actors who are involved globally in the development and functioning of PPPs (see Table 3).

The interview process was stopped on achieving information saturation, while transcription and interpretation of the data (Gill et al., 2008). This process did not involve much of the reference to the priori constructs as the intention was to explore the interviewee's engagement with the subject. The length of the interviews ranged from one to three hours. Narrative analysis (Richardson, 1995; Riessman, 2008) has been utilised to structure and discuss the spoken content. Quotations have also been used in presenting interviewees' viewpoints as well, to enhance their interpretation.

\section{Results and discussion}

\subsection{Survey results: assessing the stakeholder perspective}

A common survey was prepared for all stakeholders in consultation with the professionals. The results are summarised and discussed in the following three categories: (1) Experiences and insights, (2) Trends and measures adopted, and (3) Expectations and needs.

\subsubsection{Experiences and insights}

The first inquiry intended to ask about the overall experiences of the respondents with PPP projects. Participants were required to select one out of the given options. Figure 3 demonstrates that the experiences of $70 \%$ of respondents in PPP projects were positive and 5\% exceptional. This may be dependent on many factors such as the sectors of PPPs they are mostly involved with, or the strategies or procedures adopted in their projects. There is wide criticism on PPP due to several reasons such as, the vulnerability of poor risk allocation due to long-term nature of contracts (Asian Development Bank 2008), inadequate bidding evaluation criteria that can lead to under-investment and greater over-runs, poor contract designing, and management, or profit-sharing (Ergas 2009). But in contrast, the PPP model is one of the preferred choices in the implementation and delivery of large-scale projects (Asian Development Bank 2008). Having a higher percentage of positive experience with PPPs also indicates that housing PPPs may be a feasible option for meeting the housing needs across Europe. 


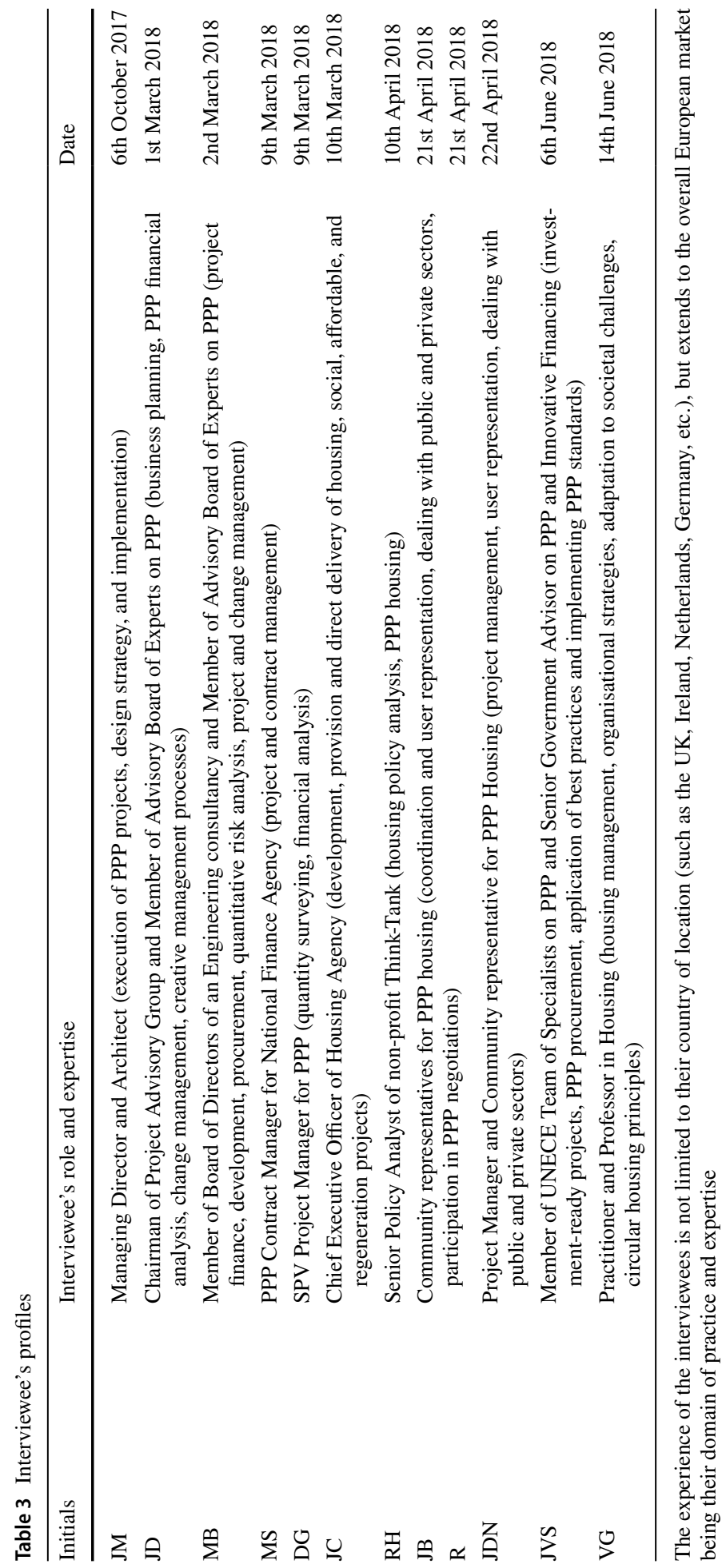


Figure 3 Experience with PPPs $(n=40)$
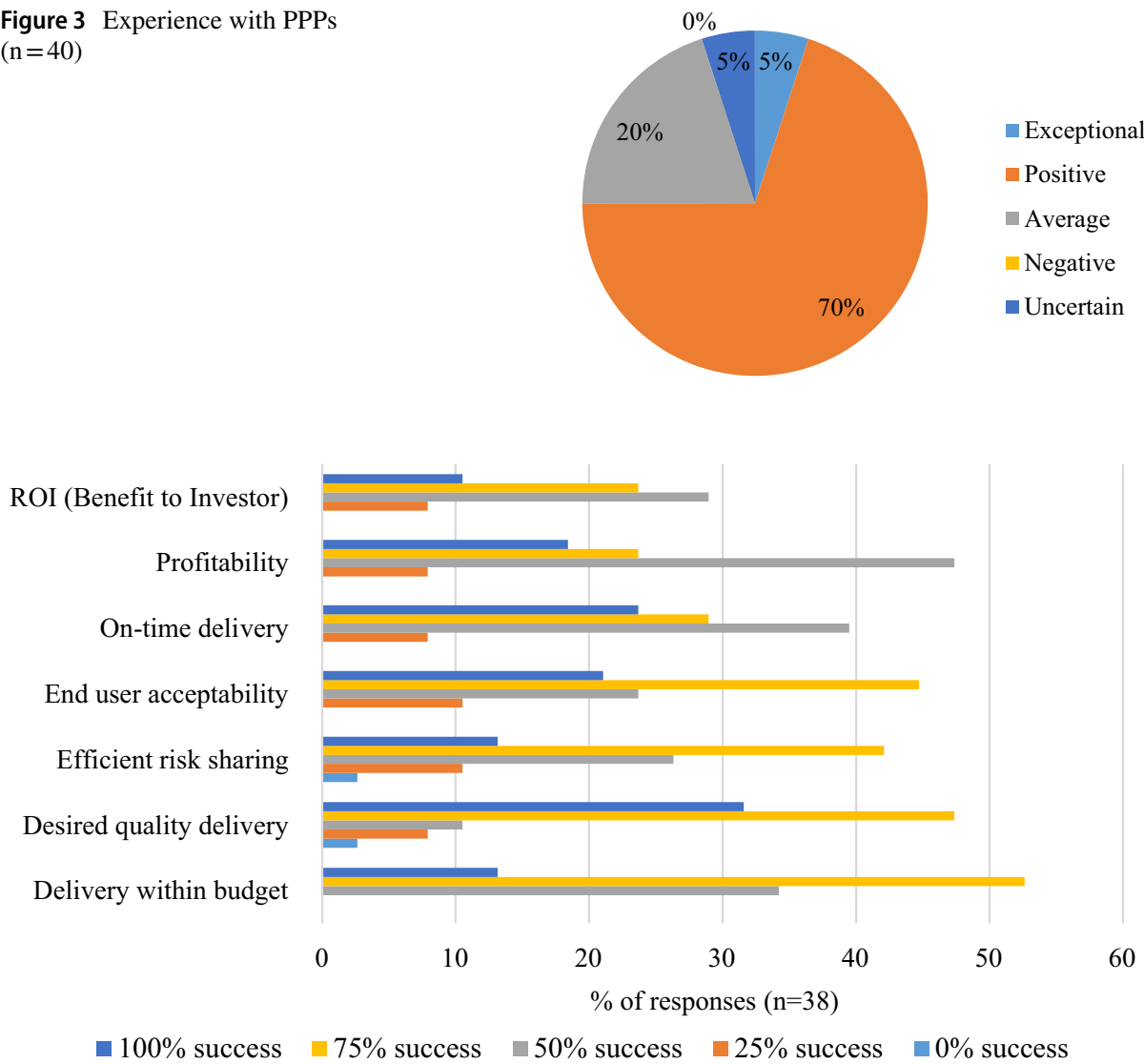

Figure 4 Success rate observed in PPPs

The experience of the respondents with PPPs goes hand in hand with the success rate ${ }^{1}$ under different aspects. The overall success rate of a PPP project depends on a range of factors and, therefore, participants were asked to rate the level of success they achieved within seven aspects of PPPs (see Fig. 4). More than $40 \%$ of respondents experienced a $75 \%$ success rate in aspects of quality delivery, delivery within budget, end-user acceptability and efficient risk sharing, and a 50\% success rate in profitability. However, the relative importance of an aspect's success rate specifically for housing sPPPs may differ. For instance, the component of the intended profit or $\mathrm{ROI}^{2}$ might not be as important as the success regarding end-user acceptability. Hence, while looking at the success rate across PPPs, it is

\footnotetext{
1 Success rate refers to the success observed in PPPs in terms of return on investment, profit, timely delivery, acceptability by the end user, risk sharing efficiency, desired quality delivery and delivery within budget. Aspects such as end user acceptability or risk sharing efficiency may also be answerable in qualitative terms and depend on the participant's perception of these aspects.

${ }^{2}$ ROI (Return on Investment) refers here to the benefit achieved by an investor by investing finance or resources in a PPP project.
} 


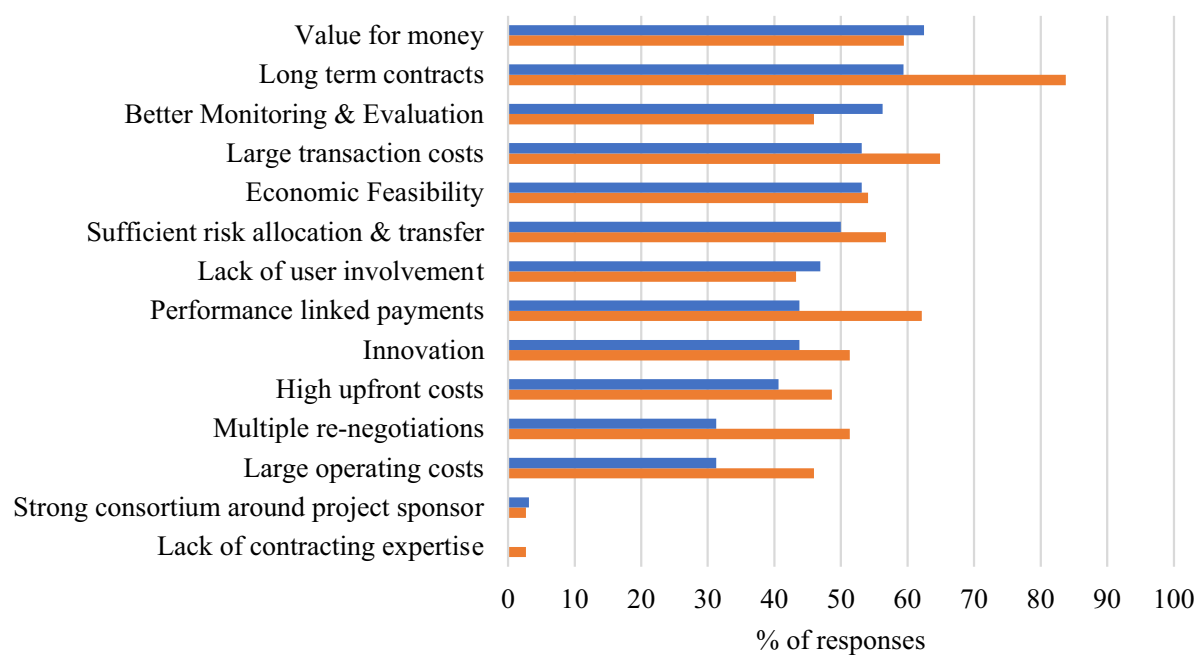

- Housing PPPs $(\mathrm{n}=32) \quad$ Other building sectors ( Social Infra, Institutional etc.) $(\mathrm{n}=37)$

Figure 5 Major characteristics of PPPs

also essential to understand which factors drive success more in housing PPPs. Thereby the critical success factors are studied in detail in further inquiries.

Moving further, an attempt has been made to identify the key characteristics of PPPs and if any of these are specifically applicable for housing PPPs. The list of categories of characteristics is based on literature and preliminary surveys. Significant characteristics such as long-term contracts or large transaction costs ${ }^{3}$ were considered relevant by about $60-70 \%$ of the respondents across other building sectors (see Fig. 5). This was also indicated by Osei-Kyei and Chan (2015) highlighting that the long-term nature of PPPs requires an enduring and stable relationship between the two parties. However, factors such as re-negotiations ${ }^{4}$ or large operating costs ${ }^{5}$ in housing PPPs are considered significant characteristics only by about $30 \%$ of the respondents. This contrasts with the relevance of re-negotiations found in the literature. For instance, a review of re-negotiations in the UK (NAO 2007), France (Athias and Saussier 2007; Beuve et al. 2014), US (Engel et al. 2011) or Latin and Caribbean (Gausch 2004) depict that 50-55\% of the PPP contracts are renegotiated across all sectors. This does show that PPPs with their long-term nature, give rise to many re-negotiations that have an impact on project efficiency. Lack of user involvement ${ }^{6}$

\footnotetext{
3 Transaction costs refer to all the upfront costs such as cost of bids preparation and execution, making and administering of the contract, re-negotiations, costs with regard to any deviations in the contract (Li et al. 2013).

${ }^{4}$ Re-negotiations involve a change in the contractual conditions, which may or may not affect the project monetarily, as well as the project schedule. They are used as a tool to address uncertainty of PPP projects and as mechanism to restore its economic and financial equilibrium.

5 Operation costs refer to the costs regarding the operation and maintenance of the facility or the service provided.

${ }^{6}$ User involvement refers to an active consultation and engagement of the end-users of the facility by the stakeholders in the planning, development and delivery process, ensuring complete transparency and spread of public awareness.
} 


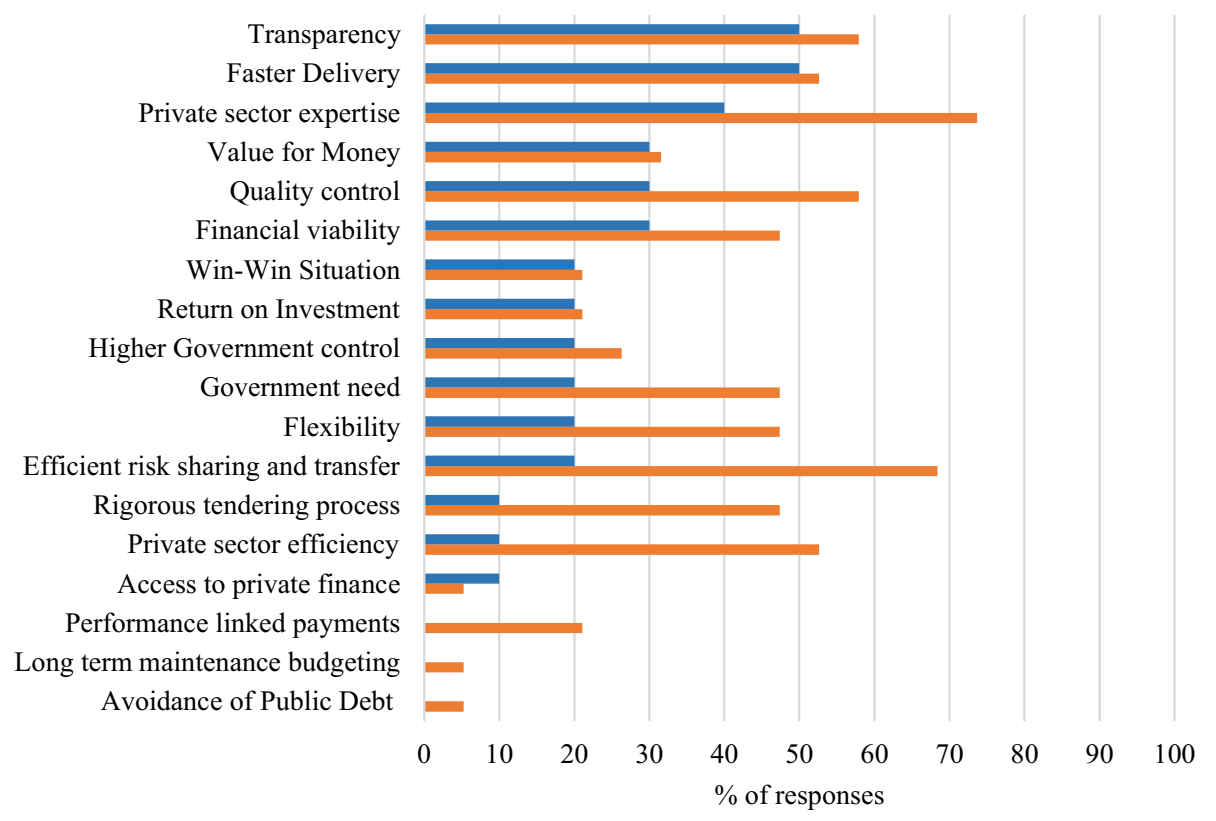

- Housing PPPs ( $\mathrm{n}=30) \quad$ Other building sectors PPPs ( Social Infra, Institutional etc.) $(\mathrm{n}=35)$

Figure 6 Criteria adopted for selection of PPP procurement

is acknowledged by less than $50 \%$ of the respondents across all sectors and requires much attention specifically in housing PPPs (Ihuah et al. 2014).

The relative relevance given to the above characteristics helps contemplate if all or any of these form the selection criteria for PPPs. The next inquiry, thereby, targets to identify the aspects required for choosing the type of procurement and that shall aid in the preliminary assessment of the suitability of PPP. The results in Fig. 6 ascertain that most of the criteria adopted for PPP procurement selection in other building sectors are not commonly adopted in case of housing PPPs. Factors like the efficiency of the private sector, risk-sharing ${ }^{7}$, greater ROI or higher government control $^{8}$ are the least adopted (less than $20 \%$ ) selection criteria in housing PPPs while they hold greater significance in other building sectors. However, risk-sharing and allocation is a significant factor for any PPPs compared to other procurement methods (Akintoye et al. 1998). The private partner is generally responsible for undertaking all the risks related to design, construction, maintenance and operation (Corner 2006). Moreover, financial viability is considered an important criterion by only about $50 \%$ of the respondents for other building sectors PPPs and $30 \%$ for housing PPPs. However, assessing the financial viability may be more important as a selection criterion to understand the bankability of a project and evaluate whether it requires support from the government in the form of subsidies or grants (World Bank Group 2019).

\footnotetext{
${ }^{7}$ Risk sharing and allocation refers to allocating the responsibility of a given risk to the partner best able to manage the same (EIB 2015).

${ }^{8}$ Government control refers to the level of control exercised by the government/ public sector in a PPP over the private partner or the SPV.
} 


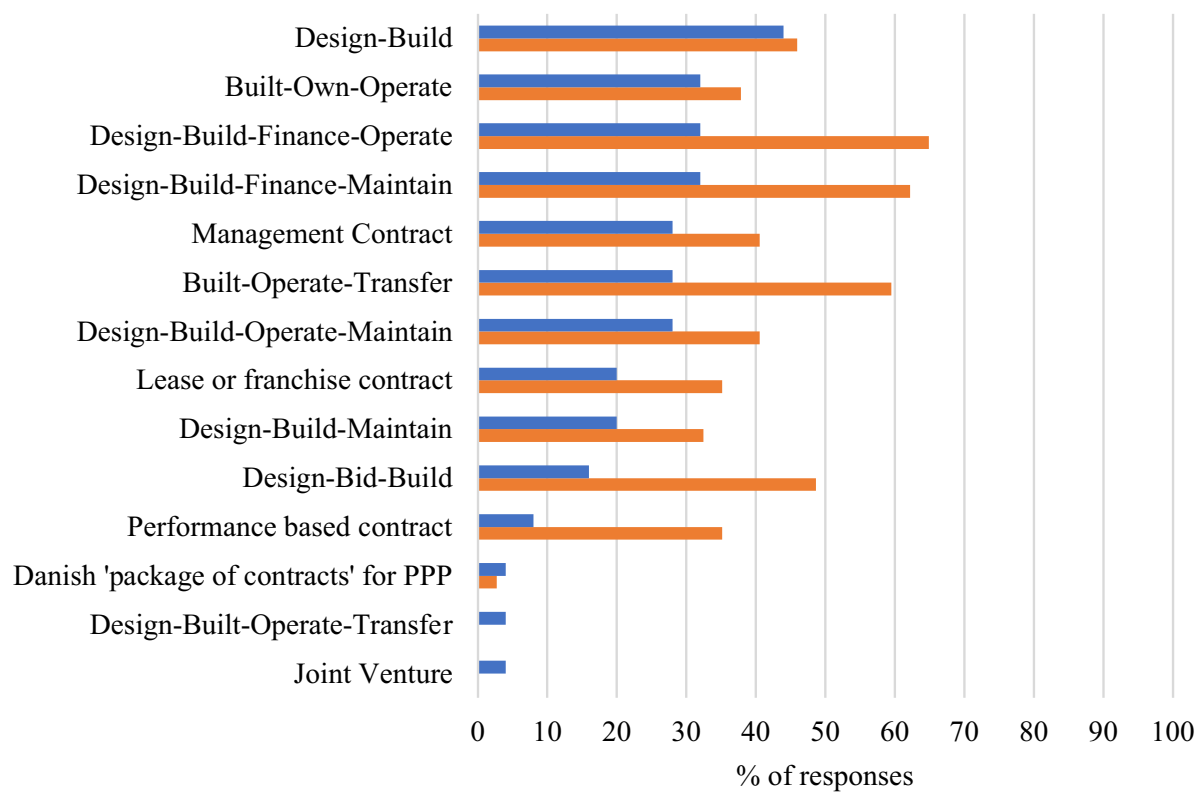

- Housing PPPs $(\mathrm{n}=25)$

- Other building sectors PPPs (Social Infra, Institutional etc.) $(\mathrm{n}=37)$

Figure 7 Commonly adopted contract models in PPPs

Faster delivery ${ }^{9}$ and transparency ${ }^{10}$ are also considered major criteria in all types of building PPPs including housing by more than $50 \%$ of the respondents.

The contract model defines the division of responsibilities, risks, and financial terms. Some of the most commonly adopted models in other building sectors are DBFO (DesignBuilt-Finance-Operate) (65\%), DBFM (Design-Built-Finance-Maintain) (62\%), and BOT (Built-Operate-Transfer) (59\%) (see Fig. 7). DBFMO or DBOF are also found to be the most common models for PPP in the literature (DOELG 2000; Lu et al. 2000; World Bank et al. 2014). This result is also well supported by the fact that PPP models are successful if private financing and management are available (Lu et al. 2000). On the other hand, DB (Design-Build), DBFO, DBFM, and BOO (Built-Own-Operate) are commonly adopted models in housing PPPs. However, other than DB, only about $30 \%$ of the respondents stated the utilisation of other models in housing PPPs. This may highlight a lack of utilisation of other models in housing PPPs although many PPP housing case studies do highlight the utilisation of models like DBFM and DBOF in the UK and Ireland (International Financial Services London, IFSL 2004; HM Treasury 2012) and DBFMO in the Netherlands (Deeleman 2013).

\footnotetext{
9 Faster delivery refers to the propagated advantage of quick execution and delivery through a PPP procurement as compared to any alternative procurement route, often because of better risk sharing and management, and performance-based payments system (Herpen 2002).

10 Transparency refers to the extent to which all the information about the project including its budgetary information, is made available for all the involved parties, the end-users and the public. It focuses on the parameters of openness, communication and accountability.
} 


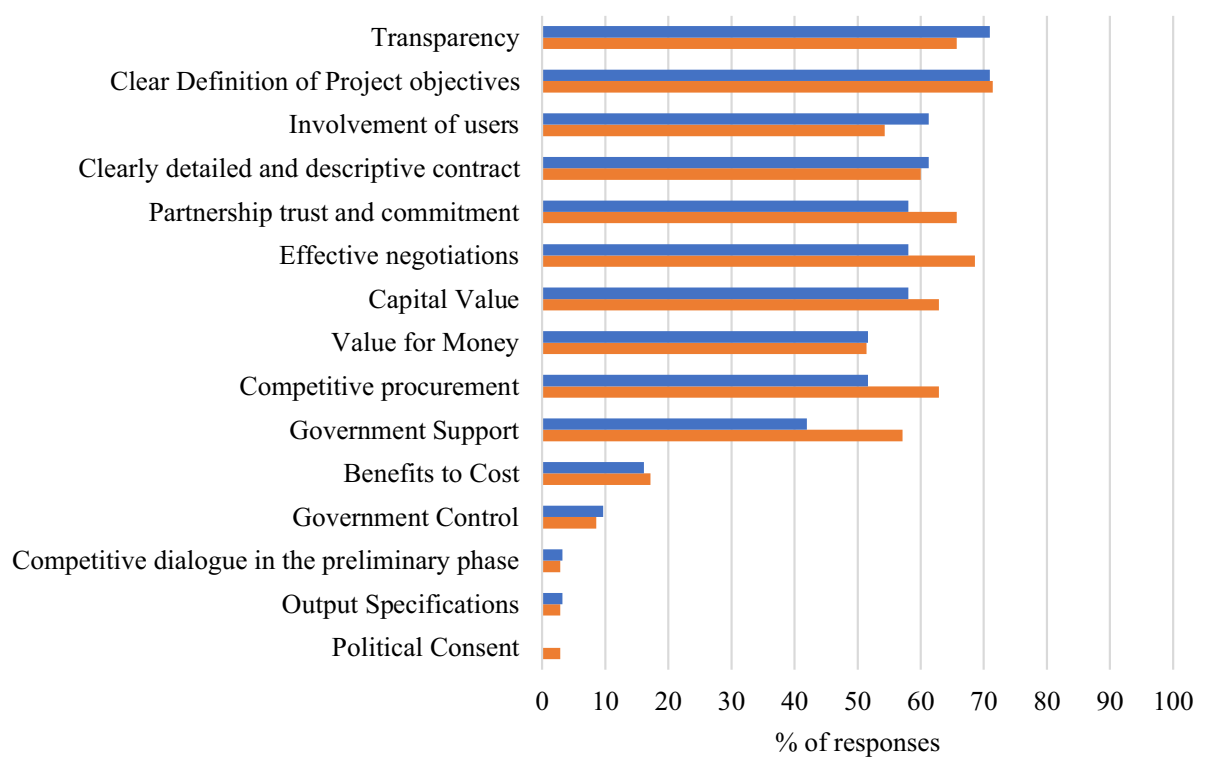

- Housing PPPs $(\mathrm{n}=31) \quad$ Other building sectors PPPs (Social Infra, Institutional etc.) $(\mathrm{n}=35)$

Figure 8 Critical success factors for PPPs

Several researchers (Tony 1996; Stonehouse et al. 1996; Osei-Kyei and Chan 2015) have discussed that the success of a PPP comprises of a range of factors, known as critical success factors (CSFs). These factors contribute to the resultant success rate as presented earlier in Fig. 4. The results in Fig. 8 outline the weight given to each of the given aspects as success attributes for PPPs. While mostly all the aspects are shown critical, having effective negotiations ${ }^{11}(69 \%)$ are weighted high in the case of other building sectors PPPs, and transparency $(71 \%)$ is considered most important for housing PPPs. Clear project objectives (about 70\%) are considered a common success attribute in both cases. Some housing PPP examples such as Fatima Mansions (Donohue and Dorman 2006) in Ireland, demonstrate how negotiations played an integral role in achieving success for the PPP approach. Osei-Kyei and Chan (2015) also support the results here by identifying risk-sharing and allocation, a strong private consortium ${ }^{12}$, users and public involvement, and a transparent procurement process as five critical factors affecting the success of any PPP project. The understanding and acceptability of the project by users, civil societies, non-governmental organisations or media governs the success of PPPs in housing (Donohue and Dorman 2006; Bissett 2008), which goes parallel to over 50\% respondents highlighting the involvement of users as a critical success factor. Also, it is thought-provoking to observe that factors such as government control or political consent are not given any importance (less

\footnotetext{
${ }^{11}$ Negotiations in a PPP refer to the skill of having an effective dialogue between the parties, to develop the contract clauses as beneficial to each of them. Often the type of bidding process adopted governs the effectiveness and level of negotiations taking place.

${ }^{12}$ Strong private consortium refers to a consortium which is financially capable of taking up the PPP project and adequately competent (Chan et al. 2010).
} 


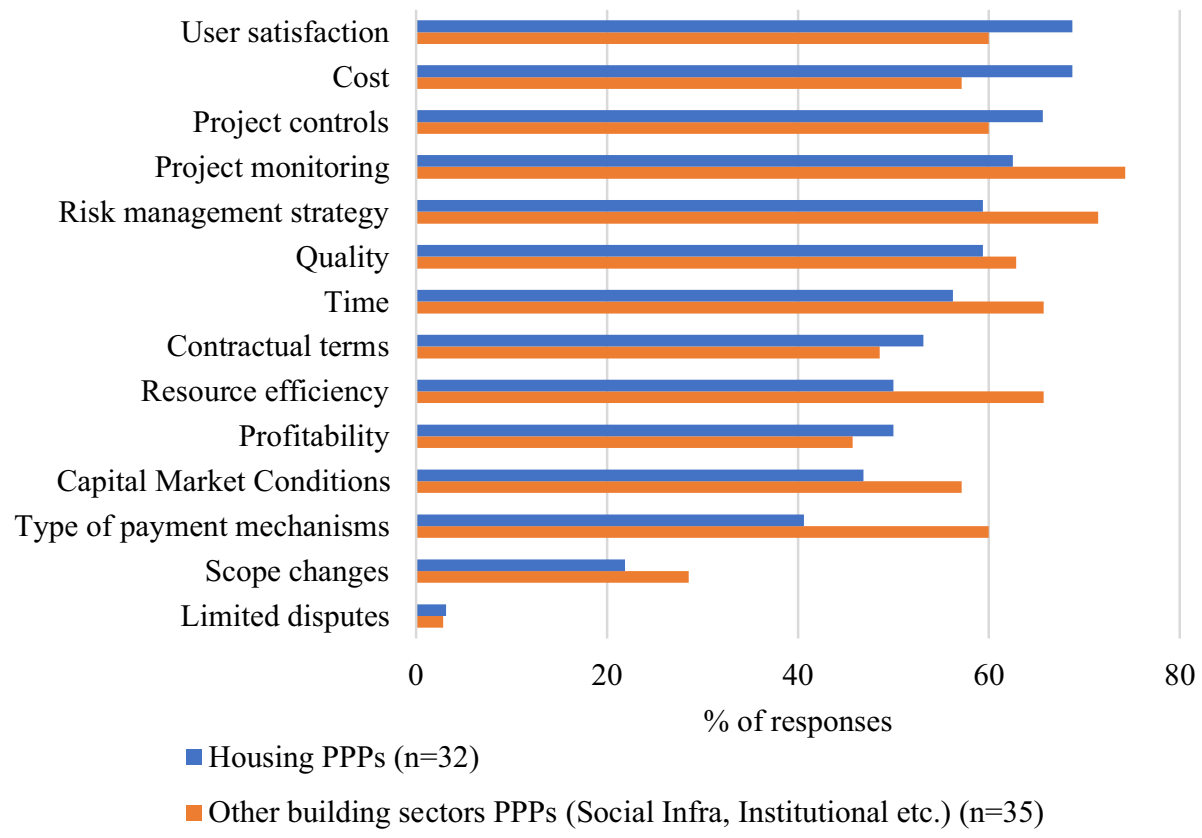

Figure 9 Performance indicators for PPPs

than $10 \%$ ). Political support ${ }^{13}$ is essential to allow for smooth processing and obtaining approvals for expenditures on public projects (Service Works Global 2015). The UK is an example of a country with whelming political acceptability of PPPs (Hardcastle et al. 2005). The degree of government control is also accountable for the success and performance of a PPP and should be given due importance (Estache and Saussier 2014). A stable pipeline of projects, efficient procurement processes, and having a diverse market for project finance are also considered some of the key determinants of the success of PPPs (Service Works Global 2015).

While the above factors gave an understanding of critical aspects contributing to the success of PPPs, the next query identified the performance indicators (PIs) that are utilised to measure the performance of PPPs. Having these indicators aid in taking an appropriate corrective course of action as and when required. The Chair of Economy in PPPs, Paris (Estache and Saussier 2014) highlighted aspects such as optimism bias ${ }^{14}$, quality of procurement process ${ }^{15}$, the institutional context ${ }^{16}$ and renegotiations that drive efficiency and performance of PPPs. Almost all the aspects shown in Fig. 9 are considered as important indicators for project performance by about $60 \%$ of respondents and higher in both housing

\footnotetext{
13 Political support refers to a committed support of the government and the current political parties to allow smooth development of the PPP.

14 Optimism Bias refers to the tendency of the involved parties to underestimate the project costs, duration or the occurrence of an uncertainty or risk in PPP (Mott MacDonald 2002).

15 Quality of procurement process refers to the level of discipline, competitiveness, and transparency involved in the process and the execution of the work in accordance with the specifications.

16 The institutional context refers to the policy, legal framework, resources and incentives that strongly influence the project outcomes in a PPP development (Matos-Castano et al. 2012).
} 


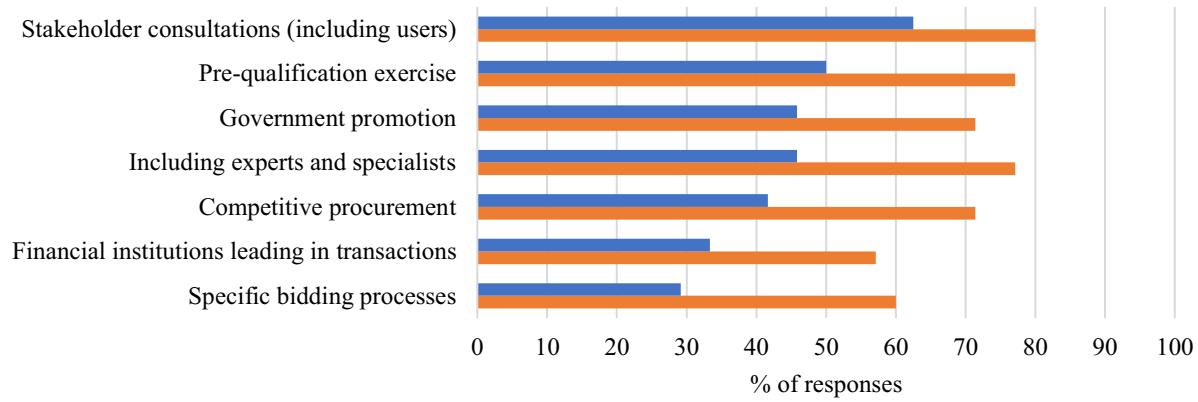

- Housing PPPs $(\mathrm{n}=24) \square$ Other building sectors PPPs (Social Infra, Institutional etc.) $(\mathrm{n}=35)$

Figure 10 Common implementation measures adopted in PPPs

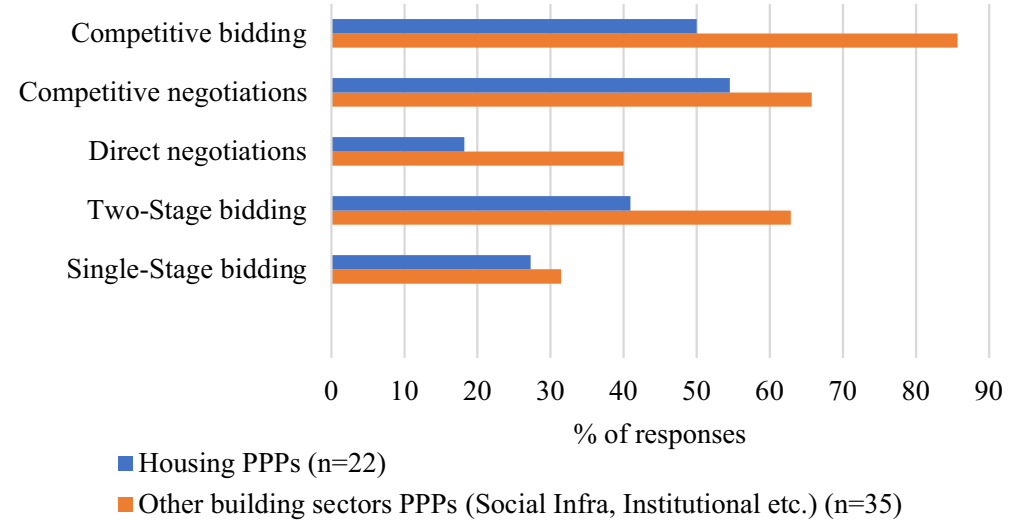

Figure 11 Bidding approaches adopted in PPPs

and other sectors PPPs. The approach adopted to regulate the specific nature of the PPP contract (i.e. concession, construction, maintenance, etc.) forms the institutional context (Estache and Saussier 2014). Performance monitoring is essential for PPPs being longterm contracts and, therefore, requires adaptation through the time.

\subsubsection{Trends and measures adopted}

Many of the economic, political, internal and external pressures create the need for adoption of certain implementation measures such as pre-qualification exercise or user consultations that must be followed to evaluate and mitigate the risk factors, which may generate over time in PPPs ( $\mathrm{Li}$ et al. 2000). This investigation, therefore, aims to understand the measures adopted in the practice of PPPs (see Fig. 10) to assess their suitability for housing PPPs and the sensitivities attached to those measures.

It is interesting to note that measures such as stakeholder consultations, pre-qualification, experts' inclusion or competitive procurement (all above 70\%) are most commonly adopted in other building sectors' PPPs, however, are less popular among housing PPPs. They must be explored for their benefits such as greater transparency, fine-tuning the allocation or encouraging collaboration in housing. Constant and healthy communication 
among all stakeholders and parties involved has been given higher importance in previous research as well (Li et al. 2005). Less number of responses for housing PPPs in this investigation may also highlight an overall lack of adoption of such measures in housing PPPs.

The type of bidding process adopted is crucial in procuring a PPP project within any sector. The nature of the project type might contribute to defining the appropriate choice of the bidding process in the respective context. Hence, an inquiry was focused on observing which bidding processes are utilised more in which sectors. Competitive bidding (86\%) is the most common type of bidding approach adopted in PPPs in other building sectors, along with a two-stage or multiple-stage bidding process (63\%) as presented in the results (see Fig. 11). Much of the literature also supports that competitive dialogue is most commonly adopted in EU PPPs followed by competitive negotiations (Eldrup and Schütze 2013; World Bank et al. 2014), as they specify all types of details and help in avoidance of costly renegotiations (Carbonara et al. 2016). Several factors affect the transaction costs in PPPs such as project size, country, economic sector, procurement time, complexity and number of bidders (Dudkin and Välilä 2005; Farajian and Cui 2010). Thereby, choosing optimal bidding procedure to minimise the transaction costs during the PPP procurement is also a sought-after quest (Soliño and de Santos 2016). Notably, direct negotiations have been given low preference by the respondents, and even lower for housing PPPs (18\%). This could be due to the absence of competitive pressure to be efficient and manage risks most effectively in direct negotiations, thereby impacting the value for money (APMG, 2016).

While the experience of the respondents has already been inquired for the most common contract models adopted (refer Fig. 7), the next open inquiry followed for the most suitable contract models and financing process for PPP in the housing sector. Many participants highlighted the BOT, DBFO, DBFMO, and DFBO as the most suitable models for the banks' lending to the Special Purpose Vehicles (SPVs). Banks are also considered as the frontiers of housing PPPs as they find a scope there to generate profit (Amann and Mundt, 2005).

About the financing process for housing PPPs, participants suggested various routes such as (1) government funding the capital investment, (2) having a strong financial counselor providing multiple financing options to the government, (3) developing social infrastructure or any linked investment such as public space along with housing, and (4) partnering with financial institutions and utilising developer's financing for housing PPPs. Some participants also suggested limited and non- recourse ${ }^{17}$ finance, for housing PPPs. Few other suggestions were regarding reliance on tax paradise or a combination of equity and debt funding with other types. One such combination can be observed in the LimitedProfit Housing Associations (LPHA) model (Amann 2009) of housing PPPs in Austria involving market mortgage loans, low-interest public loans, and equity.

Even while adopting set procedures or processes, PPPs hold long and complex schedules and require full preparation for any event of failure or uncertainty. Most of the participants insisted on undertaking a thorough and detailed analysis of the project with the involvement of experts, and a ready insurance plan. This is supported by many studies that having a robust risk mitigation mechanism with guarantees, insurance, and step-in rights, or an early contract termination provision aid in dealing

\footnotetext{
17 Recourse financing refers to financing that gives the lenders full recourse for the shareholders' cash flow or assets for loan repayments in case the SPV/ private is unable to fulfil the loan. In case of limited or nonrecourse financing, lenders get limited recourse to the assets (World Bank Group 2016).
} 
Social Infrastructure projects ( eg. Hospitals)

Transportation projects

Social housing projects

Government projects

Educational projects

Commercial projects

Other building projects (eg. Mixed use)

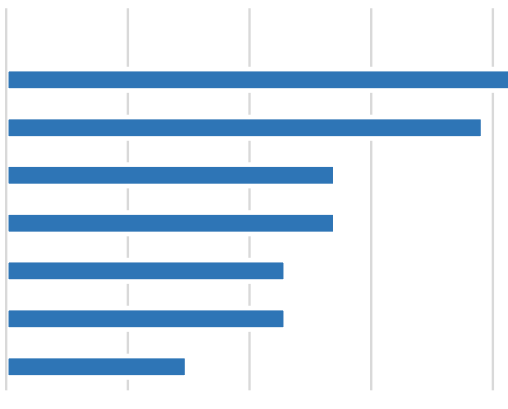

$\begin{array}{lllll}0 & 20 & 40 & 60 & 80\end{array}$

100

$\%$ of responses $(n=37)$

Figure 12 Type of project suitability for PPP

with uncertainties on the way (Akintoye et al. 1998; Grimsey and Lewis 2005; OseiKyei and Chan 2015). Also, the type of contract model (BOT, DBOM or DBFM, etc.) ensures the clarity of provisions incorporated. Few respondents also suggested six primary success factors that can form a strategy to deal with uncertainty or failure as following: (1) good relationship with client, end-users, subcontractors and suppliers, (2) minimal subjective KPIs, (3) a functioning help desk to deal with requests and complaints, (4) explicit and realistic performance standards and criteria, (5) quality of service delivery per output specification, and (6) use of Just-in-Time approach compared to a prescheduled maintenance regime. It is interesting to note here that no separate strategies were mentioned for housing and the suggested measures seem generally applicable to all or most PPPs.

Most of the participants stressed the need for regular dissemination of information and contract management by terms of the agreement. An independent agency should periodically monitor for the government over the long-term, appointed through fee sharing or as a special advisor to advise, mediate and monitor these risks, especially during the assessment process and evaluation of PPP proposals. The identification should be done in the early stages, through Work Breakdown Structure (WBS) and distributed to the best parties able to manage it. Few participants also suggested utilising risk allocation models to manage the process of risk-sharing more effectively.

While exploring the PPP trends, it is thought-provoking if any compromises are also being resorted to in this process in practice. Most of the participants expressed that in a race to achieve the timeline of the project, the cost is often the bearer in the process. The cost can also be affected by the decline or change in demand for the service (e.g. school population decline in a school PPP). PPPs need much flexibility due to their often-long-term nature. Many participants also assured that quality is never compromised as it is usually linked to service payments to ensure able service delivery. This ascertains that there are often financial compromises and one must hold a concept of renegotiations in the contract. Few participants also said that in times of missing technical, legal, institutional, financial or regulatory framework, these factors of time, and cost are highly compromised. Also, there exist compromises over having an adequate and holistic vision, planning, and due diligence. 


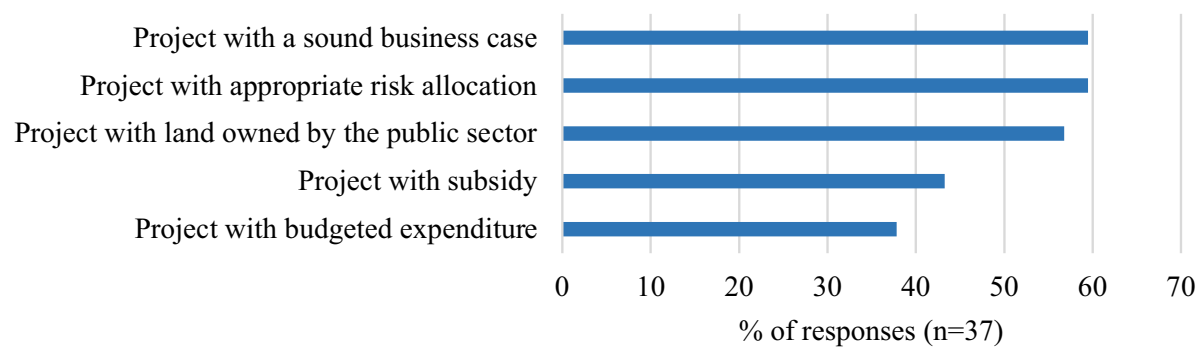

Figure 13 Project conditions suitable for PPPs

Figure 14 Satisfaction among social and political communities $(\mathrm{n}=31)$

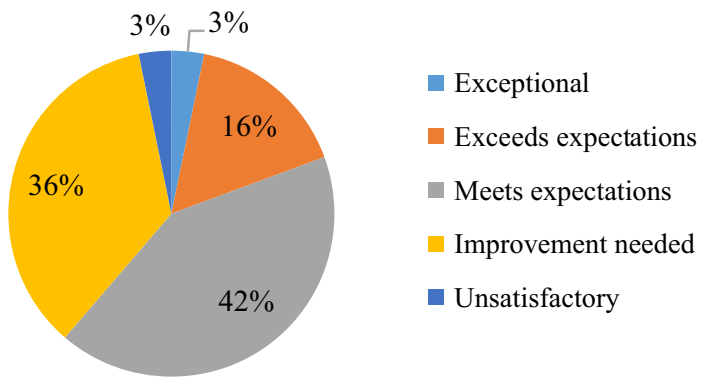

\subsubsection{Expectations and needs}

This section focused on gathering the requirements of the PPP industry, the gaps within, and what can help to fulfill those needs. It began by first assessing the perceived suitability of PPP in different building sectors to understand the perspective of the participants on its application feasibility in housing. The respondents were asked to select one or more types of projects suitable for PPPs based on their experience. The list may not be exhaustive but represents broad typologies prevalent for PPP procurement as understood from literature and preliminary surveys. Figure 12 reflects the opinion of the respondents about different types of projects and the associated suitability of PPPs.

Social infrastructure projects were considered most suitable by over $80 \%$ of the respondents. This may be due to the high plausibility of achieving returns in these projects, e.g. through user-pay systems. Infrastructure projects are also considered most suitable as they entail comparatively fewer risks and failure factors and, therefore, are preferred for PPP models (Flanagan and Norman 1999; Gausch 2004; EIB 2008; Eldrup and Schütze 2013). However, only about $50 \%$ of respondents considered housing, governmental, commercial or educational projects suitable for PPPs. On the other hand, the conditions represented in Fig. 13 seem generally common for all projects' suitability. However, the concept of subsidies was not given much weight comparatively, which is a relevant concept for housing PPPs to ensure financial stability and support (World Bank Group 2019).

The functioning and success of PPPs, especially for housing, largely depend on its acceptability among social and political communities (see Fig. 14). For example, St. Michael's Estate PPP project (Bissett 2008) collapsed due to the unacceptability at the communities' end and the differences that arose thereby; while Fatima Mansions PPP (Donohue and Dorman 2006) was a success in these terms, with exceptional acceptability at the communities' level. While $42 \%$ of respondents indicated that the satisfaction level 
Figure 15 Suitability of PPP for housing $(\mathrm{n}=37)$

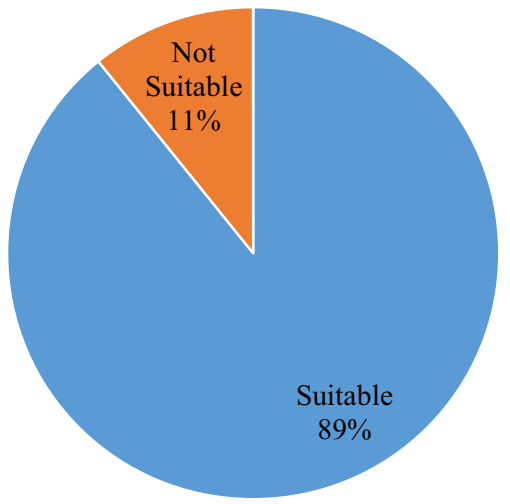

meets the expectations, about $36 \%$ also highlighted the need for improvement. This is an important factor and should not be left ignored. Many cases have been studied (Donohue and Dorman 2006; Bissett 2008; Sykorovà 2013) where PPP models have shown several deficiencies, and these results pinpoint towards improving them.

There is also a need to understand what initiatives from the public sector could draw interest for the private sector into PPP. A strong rationale for PPP policy, clear picture of the project plan, backed by well-thought-out legal, regulatory and investment framework are essential for the private sector. These are followed by transparent processes, flexibility, better consultations, the absence of corruption, and the scope of profitability. Most of the participants stressed taking care of the private's interest, having bankable projects with a stable project pipeline, holding reciprocal interests, incentives system and guaranteeing profitability and revenue in the long-term. An established pipeline is considered beneficial by the private sector to ensure sound business cases and public acceptance. Furthermore, some participants ascertained that the private sector also looks for regulation support, payment guarantees, having performance-based payment systems in place, land allocation for PPP, capping on the exchange rate, tax reduction on construction material import and strong political support as well.

Few participants suggested, encouragement of spontaneous proposals for PPP, strengthening of the legal and institutional framework, having soft investment requirement criteria, an environment devoid of any complex bureaucratic procedures, and political risk guarantees as some of the ways to attract the private sector. The legal requirements required to deal with the regulatory risks (Finnerty 1996) and a good governance structure (Badshah 1998) has been strongly reflected in the literature as well. Having a shadow bid from the government that can act as a reference for the private sector to improve upon and aid in reducing transaction costs and providing the scope of innovation also attract the private parties a lot into PPPs. An economic study (Akitoby et al. 2007) highlights three significant factors through which the public sector could ensure the provision of high-quality PPPs delivered efficiently. These include a strong legal framework, established processes for selection and implementation of PPPs along with the involvement of finance ministry in this context, and contractual obligations that form the basis of PPPs and help in determining the financial risks incurred by the government. 
Table 4 Constraints and enablers for involvement in Housing PPPs

\begin{tabular}{ll}
\hline Constraints & Enablers \\
\hline Lack of bureaucratic understanding & Land provision for PPP by the government \\
Lack of effective policy & Financial advisors' experience \\
Inequitable risk sharing, public accountability & Government controls land for development \\
Lack of regulation of long-term contract & Institutional strength, improved transparency, and the \\
Unreasonably calibrated bargaining and different & rule of law \\
understanding of risk & A single multi-disciplinary not-for-profit entity with \\
Absence of clarity, transparency, profitability & experience in implementation on a PPP basis, that \\
Inefficient legislative and government approvals, & performs a buffer function between public and \\
stakeholders marginalisation & private partners \\
Lack of certainty of the revenue stream, and proper & Approval for mortgage financing \\
risk allocation & Government subsidies or guarantees, clear govern- \\
Lack of risk allocation to developers & ment commitment \\
Lack of local authorities dealing with PPPs & Presence of project experts \\
& Model contracts, consultants with competence \\
\hline
\end{tabular}

It is interesting to note that $89 \%$ of respondents believe in PPP being a suitable approach for housing and must be explored (see Fig. 15). This reflects further on the purpose of this study to explore PPP suitability ${ }^{18}$ for housing. Many PPP housing projects in countries like the UK and Ireland (IFSL 2004; Donohue and Dorman 2006) also substantiate a positive perception of PPP suitability for housing. Moreover, with the increasing requirement of subsidised housing in many European countries (Eurostat 2017), new approaches like PPP are required to meet the demand, but there is reluctance in the adoption of the model seemingly due to unaccounted factors in a local context.

To further this chain of inquiries leading to housing PPPs, it is important to understand the strategies that could be utilised to attract the private sector into housing PPPs specifically. Most of the participants focused their concerns on regulatory support from the government, incentivisation, and financing. Additionally, the scope of having a reasonable rate of return and profit-making for the private sector as essentials in making this successful. Payment guarantees or buying of a certain number of houses by the government in case private sector fails to sell them, strong political support, flexibility, formulation of effective policies towards PPP housing, land for housing PPPs, subsidies, adapted housing legislation form the regulatory support from the government's side. Developing mixed-use facilities, for example, by adding retail development with housing can help in generating additional income and value for housing PPPs. Low-interest bank lending and developing a functional micro-credit long-term financing structure for the informal sector of society for affordability are some of the strategies suggested by many participants. They also suggested the idea of shared ownership to make capital gains attractive, initial public offering (IPO), involving civil society, and creating public awareness on the benefits of PPP.

As a final step, it was paramount to understand what constraints or enables private partners to get involved in a housing PPPs. This aids in pointing out the key factors that restrict the involvement of private partners as well as the key enablers encouraging their involvement in housing PPPs (see Table 4).

\footnotetext{
18 Suitability refers to the appropriateness and fit of the PPP approach for housing in terms of meeting the demand, cost-effective delivery, providing a regulated supply, bringing a socio-economic balance, and addressing the housing affordability and accessibility challenges.
} 
The survey results discussed above were superimposed by expert interviews, on the subject to attain a detailed perspective and understand the reasoning behind the prevalent practices. The next section throws light on the viewpoints of the experts' interviewed.

\subsection{Interview results: Investigating the key personnel}

The interviewee's viewpoints are collated in this section with the focus lying on the flow of experience of the PPP experts and actors, thus making sense of the narrated events and actions. The results are summarised in the following categories: (1) The domain of PPPs, (2) The take on PPP in housing, (3) Challenges and concerns, and (4) The path to success.

\subsubsection{The domain of PPPs}

As described by JVS (a member of Team of Specialists on PPP), the irony is that most people focus on PPP only as a project. Using PPP as a strategy and not as a project also helps in drawing in the interest of the private sector. The government is required to understand PPP as a strategic decision. The strategy can be re-evaluated and improved upon, and the PPP laws can be revisited time and again to increase the success rate. Dealing with PPPs on a project-to-project basis often does not give a wholesome perspective.

There are three main aspects associated with failed PPPs, pointed out JVS: firstly, the act of corruption, secondly, having a wrong business case, and thirdly, the brush off between how much money can be spent vs. how much is actually spent. "Often the motive of profitmaking fails the PPP and not the PPP itself", stated by JD (a member of the advisory board of experts on PPP). He seconds the opinion of JVS that PPPs should be used as a problemsolving strategy, to achieve the objectives, rather than just a project. For example, for a school building project, the focus shall be on the education system delivery and not just on constructing a school building. Further, JVS outlined three components as the core to PPP, the first one is having an endowment fund for not only the private sector to build something but also to help gauge the financial advantages. Secondly, having a substantial competition that will ensure good value for money and a healthy balance of options. And lastly, having an open market.

Like JVS stated, "The idea is to take the responsibility of the delivery away from the government". In any PPP, the interests of the private sector must also be safeguarded with the benefits such as long-term payment, land at a reduced price, and a portion of the housing to sell. This, in turn, helps them deal with market retail, as well as contributing to society by providing affordable housing. As DG (a PPP practitioner representing the private sector's interests) rightly puts it, "Value of the project has to be bigger to interest the private sector and also a guaranteed fairly defined return is essential". Debt, equity or pension funds, all form sources of capital and funding for a PPP. Therefore, for a private partner, the unitary charge is based on what returns they are looking at and what interests they can borrow for. It is also important to take care of different teams' share of profits. There are several profits such as construction teams', managers', banks', or FM's profit. They are realised only at the end and, therefore, require a margin to be considered in the beginning.

Competitive biddings are usually the common bidding process in PPPs in Europe (Eldrup and Schütze 2013; World Bank et al. 2014). The same is also confirmed by DG for PPPs in Ireland which are mostly competitive biddings and not direct negotiations. While competitive biddings are extremely important, direct negotiations are often more transparent, as pointed out by JD. The bids are assessed on technical, functional, quality, design 
and cost aspects separately. Also, JC ascertained regarding the procurement model, DBFO is the most utilised model with unitary payments in Ireland for housing PPPs and even schools.

\subsubsection{The take on PPP in housing}

Another view on PPP in housing is highlighted by JD that it is at an early stage and is not clear yet as to what can be the best unitary charge for housing PPPs over the next 25 years. Many technical reasons such as money or expertise are pointed out by MS (practitioner in PPP) that needs a thorough investigation. This view is also supported by DG calling it the beginning of PPP in housing, with its growth depending on the current housing situation in a country and its demand.

As JVS said, it is vital to focus on the aim of the project. For example, if the aim is to provide housing for refugees in the current context, then the number of houses and their fast delivery is more important than their quality. Therefore, the strategy shall be developed around the purpose. Housing is required that lasts for years, with good quality and faster delivery. Realising that housing is a strategic decision and not just looking at other PPPs that worked for money, PPP would be extremely suitable for this.

Also, VG (a practitioner and professor of housing) added that PPP housing in the Netherlands functions as corporations being set up for housing. The corporations can build houses of all categories for all income level groups depending on the local need and situation. They are provided with the money for building the first lot of housing by the government. Afterwards, the houses are built and maintained by them from the income generated. This revenue leads to setting up a mobilisation fund. Similarly, it is happening in the UK or Germany. The need for such corporations in today's cities is also stressed upon by JVS. There is also a system of subsidies paid by the government. For housing, subsidies are given based on income levels. The hospitals in the Netherlands also work on a PPP with a subsidy system from the government.

Generally, for a PPP housing, an integrated development should be the idea, by having a mixed tenure housing, as recommended by JC (a chief executive officer of Housing Agency). The housing mix shall have enough public housing. For example, in Fatima Mansions PPP housing in Ireland (Donohue and Dorman 2006), as confirmed by JDN (project manager and community representative), the initial percentage of social housing units versus private units was only $20 \%$. Later, the private units were reduced further with added pressure from the community. He further stated, "In Ireland, the PPP model in housing was successful in Fatima Mansions, but not elsewhere". Another PPP housing project in Ireland collapsed because the council ignored the project viability issues and promised a higher percentage of social housing, leading to pulling out of the bidders in the early stage itself. There should be a mix of housing types to uphold socio-economic balance and social integration. Also, providing a development opportunity for private retail or ownership housing and other facilities along with social and affordable housing would be ideal.

"In any PPP, there is a physical, social and economic investment required regarding housing. The common factor in all of them is the value of the land. Fatima Mansions was driven due to the value of the land", JDN stated. He also pointed out that while student housings or voluntary housing associations can borrow money from the market, the council cannot and, hence, should target low-income households. For example, in St. Michael's PPP Housing in Ireland (Bissett 2008), the people were not offered any money for maintenance, etc. Two ways to provide housing (1) by bringing in Housing associations as they 
can borrow money very cheap (a slow as 4\%), and (2) by ensuring that it remains as a notfor-profit, are also suggested by JM (an architect).

In the St. Michael's housing, the PPP was utilised as a mechanism to take the people off from the land. The significant loss was the elimination of public housing. The state traded off the land with the developer. The community representatives, JB and R, expressed their displeasure over the fact that the developer was interested only in making maximum profit and not in community requirements. There was a lack of transparency in the process, and the entire land was given to the private developer with only a small share given back to the community. Also, as JD puts it, PPP housing fails primarily because people try to get finance-driven solutions and it is a social issue. While JB stressed that social finance mechanism could be utilised to build the housing, with a provision for low-cost finance by the EU, JVS suggested a system of capping the revenue to be put in place. He added, "In the Netherlands, the SPV has to invest back as per the policy, over a certain percentage of the revenue generated". From the insights of these experts, the acceptance of PPP for housing among the political and social communities comes across negatively.

\subsubsection{Challenges and concerns}

Some of the primary nodes are pointed out by JVS: long-term cost, maintenance cost, and initial capital investment, which are essential to evaluate a PPP's risks and value for money. According to MS, the chances of winning a PPP tender are about $25 \%$ with a huge investment in bidding costs. Also, JC and DG emphasised the concern with high bidding costs and lack of estimation of bidding costs during feasibility analysis. They also suggested making the bidding process simpler to reduce overall costs. The state should also pay a portion of bidding costs. Often PPPs fail because governments lack understanding of the PPP concepts, level of complexity, estimated costs and risks involved, as shared by JD. Risk-sharing always has a price and quantity attached to it. Moreover, the risk profile can change as time moves forward. For example, in concession PPPs, the risk profile which may be quite high initially, may change after 3-4 years when the project touches more realistic figures. He further believed that private partner can plan better about capital expenditure versus operational and maintenance expenditure. For example, in a typical British PFI/ PPP, capital expenditure amounts to about $30 \%$ of the cash flow and the rest $70 \%$ goes into operation and maintenance. However, everyone only pays attention to capital expenditure and ignores the rest.

Often the undertaking bodies focus on how to do PPPs instead of what is that they need to solve, pointed JD. Also, according to JC, another major problem is with the skills and scale of PPPs. Too much bureaucracy makes the process much costlier and disincentive. For example, in housing PPPs in Ireland, lack of transparency and distrust among the Council and the residents were the biggest problems. Although PPPs are long-term contracts with large transaction costs, they have the potential to yield equally good value for money.

Having private capital at risk ensures their performance and efficiency in delivery. Like JD puts it, all of this also stems from the expertise dealing with the estimation and identification of risks. It was clearly stated by JVS that the government usually doesn't know about risks because they usually hold a budget for everything, and hence they do not evaluate. However, the private sector understands risks better. The risks are best anticipated by the personnel specific to the subject expertise. Therefore, the involvement of expertise is essential. He also stressed on achieving more quality by changing the system. Investing less 
money by working on the strategy is also an outlook to be considered. While the economic feasibility of the PPP should be pre-assessed, there should also be room for re-negotiations. Further, MB expressed that it would be significant for the financial body to be involved in every process. This is also supported by MS and JVS stating that they take care of highlevel risks and keep an eye on the cash flow. Financial institutions support slow and steady PPPs. Often, the legislation also becomes a hindrance to adopting PPP and may require the laws to be modified to accommodate PPP.

Concerning PPP housing, market risks form the most significant component. What if units will not sell? What if the developer goes bankrupt or the banking system collapses? On this note, DG pointed out a new phenomenon for assessing a bank's collapse, known as the stress-testing ${ }^{19}$ of banks against bankruptcy. Some other concerns about poverty and anti-social behaviour also affected the success or failure of PPP in Ireland. As JDN also added, "The challenge in Fatima PPP housing was regarding dealing with the government and the developer, for local labour clause or arrangement of jobs for local people. They held a continuous social challenge. The key critical concern is when the transfer of an asset from the public to private appropriate".

\subsubsection{The path to success}

Initial assessments and appraisals are essential for a PPP's success. In the case of housing PPPs, the involvement of residents and consultations with developers who could assess the reality of the project was necessary. According to JC, it is critical to get the balance between public and private sector right and manage the expectations of both the residents and the politicians. Therefore, experts with specialisations are required to deal with the varied concerns. The biggest success in Fatima PPP, as expressed by JDN, was regarding the involvement of the residents and sharing a trustful relationship between the council and the users. This opinion is supported by JD and JVS by stressing the need for inclusion of local people and users, looking at the additional value of PPP.

Housing is different from other forms of infrastructure. However, JVS and MB ascertained that a guaranteed (even if lower, say 3-5\%) return is essential to have the private sector interested in that. Involving the private partner also provides many economical and functional benefits. For example, JVS explained, in a sector like roads, PPP gave about $20-25 \%$ cheaper costs than traditional procurement in the Netherlands, due to the integration of building and maintenance. The focus was on optimising the design to minimise maintenance and organising the maintenance work in a way that does not impact the functionality. PPP is a trigger for the government to get the policy to implementation right and not just for money.

Initial feasibility analysis, appraisals and cost-benefit analysis engaging specialists and all stakeholders, open and honest communications, a well-written contract, capping of profit (often driven by market forces such as inflation), transparency and competition, all form essential milestones for achieving success. It is also essential to have flexibility and re-negotiation clauses in the contract, as it is impossible to predict accurately for 30 years down the lane. Some of the procedures to ensure success in PPPs are also highlighted by DG such as workshops, bi-weekly meetings, and an online concern register to record

\footnotetext{
19 Stress-testing refers to a computer-based simulation technique used in banking to determine their reaction towards different financial situations.
} 
discussions and decisions taken in the event of a problem. Having performance-based payment streams, interim reviews, and testing and commissioning systems in place also aid in the successful delivery and achievement of the goals. Having a strategy with re-financing and involving learning from previous experiences such as adding on the clauses in the contract according to the previous experiences and problems faced, help in avoiding them in future projects. Also, for the bidding process, a combination of competitive bidding and competitive negotiations would be most suitable.

Success is often also measured concerning the timely delivery and budget of a project. Other PPPs in Ireland are generally delivered on time and within budgets such as the School bundle 3 and 4, as shared by MS (NDFA 2018). The process involves the contract being assured within specifications and hence being achieved in time. In some of the other housing PPPs such as Cedar Brook or Hannover Quay (Park Developments 2013), the system of prefabrication system of concrete panelling was developed to help to build the project half in time, the council achieved its objective, the developer got its profit and prices of the units were affordable for the common public. As DG puts it, if one can achieve a success rate of about $40 \%$, it is quite good to continue operating in PPPs.

"The physical environment, the facilities, the success of the process and most of all, the power of having a regeneration board were the key success factors in Fatima Mansions. If people refer to PPP in housing, the only model is at Fatima Mansions". This statement by JDN does sound impactful. A balanced level of governance and procedures and not making it a bureaucratic process is equally essential. For example, setting up a regeneration board, bringing in executives and part shared agreements was very successful in the case of Fatima PPP housing in Ireland. The board worked on the relations between state, local authorities, social community, and school. They negotiated vigorously for a community facility, crèche, the enterprise and local jobs for people, and aimed to focus on the socioeconomic development. However, JVS also stressed the importance of taking care of political stability and influence, and not ignoring the political discussions. Getting cross-party agreements in-principle (especially relevant in case of changing governments), a dialogue with the press and the targeted users explaining the benefit for the people, and legal work managed behind the scenes are some of the major considerations to be taken care of for encouraging strong relations among stakeholders.

\section{Summary and conclusions}

This paper brings together the perspective of the stakeholders towards PPP in housing and other building sectors under one roof with a two-tier approach comprising of surveys and expert interviews. While the surveys studied the market perspective, expert interviews helped in gaining deeper insights and reasoning over the subject. Limited available literature over housing PPPs and the existing European PPP market scenario made it imperative to turn towards exploring other sectors wherein the findings concluded a high consideration for the suitability of PPP for housing.

The results showed a majority of positive experiences with PPPs and a varying success rate perception depending on different aspects such as profitability, desired quality delivery or delivery within budget. These factors may hold different weights in different sectors, and accordingly, the success rate for some might be more crucial than others. Long-term contracts, large transaction costs, performance-linked payments or re-negotiations were highlighted as some of the relevant PPP characteristics in housing as well as other building 
sectors' PPPs. However, there is an observed lack of user involvement across all PPPs and this is an important concern that needs to be dealt with robustly when it comes to housing PPPs. And while criteria like transparency, faster delivery, value for money or financial viability were considered significant in choosing PPP procurement for housing, many others such as private sector efficiency, rigorous tendering process or access to private finance lacked standing but are essential to be considered for housing PPPs. Furthermore, transparency, a greater degree of partnership trust, user involvement, and user satisfaction also form the critical success factors as well as performance indicators for housing PPPs.

Regarding contract models and procurement, DBFO, DBFM, DBFMO or BOT are some of the most common and suggested models for housing PPPs. While competitive bidding is mostly used in PPPs, competitive negotiations or direct negotiations may be preferred bidding approaches for housing PPPs since they are much more transparent.

The results further confirmed many measures that can be adopted for the smooth functioning of PPPs such as stakeholder consultations, experts' involvement, and pre-qualification exercise, and having proper risk allocation and mitigation mechanisms. Different combinations of financing can be considered for housing PPPs such as public and private financing, asset-based finance, limited recourse finance, or involving subsidies from the government. Provision for re-negotiations is also essential in housing PPPs to avoid financial compromises and ensure efficiency in performance. Capping of revenue over a certain percentage can prove to be a good system for housing PPPs. Interestingly, other than the UK and Ireland, Netherlands and Germany are also found to be actively engaged in PPP housing that functions more in a setup of corporations with a recurring income system, where the income generated is invested back into the housing development. So, the revenue generated from the housing itself helps in building up a mobilisation fund. Such corporations or associations may be permitted to borrow cheap capital by modifying a country's PPP legislation accordingly. This could be one of the ways to follow to develop housing PPPs as financially viable.

Another important consideration for housing PPPs is about its social and political acceptability. To ensure greater acceptability, measures such as having a clear plan for PPP, legal and regulatory frameworks, transparency, consultations, flexibility in the contract and scope of having a steady rate of return, provision for incentives, or public guarantees and low-interest loans can be adopted. Having land provision and effective policies for PPP housing, and developing mixed-use facilities such as incorporating commercial or institution along with housing, could also attract the private sector effectively.

Specifically, in the case of housing PPPs, some of the basic principles need to be focused upon at the foundational level about the PPP approach. Adopting PPP as a problem-solving strategy and not as a profit-oriented project may aid in catering to the real objectives in question and develop a systematic solution delivery. Moreover, having profit as a driving factor could result in a failure. The focus should rest on 'how' it is to be done that just 'what' is to be done. Also, to enable a realistic budget planning and certainty, the percentage of maintenance costs versus capital investment in the long-term costs must be evaluated for all the risks. For this purpose, the private sector may have a better understanding of planning the costs. However, risk evaluation must be carried out by the personnel of the subject expertise. Such initial appraisals and assessments, engaging experts, and transparency are crucial for optimising the performance.

Summing up, a housing project often requires many concerns to be addressed, such as social security, quality of housing, spaces for public gatherings or children, the need to curtail crimes, or energy efficiency. The PPP strategy shall be developed around the objective of the housing. Some provisions, for instance, having the land at a reduced price, or a 
portion of the housing for private sale or incorporating retail or institutional services could help the private partner deal with the social rental and maintain their interests as well. Also, involving the community from the start is extremely essential. This could be executed by having a representative board for the community participating in all decisions and having access to all information. PPPs, therefore, may be used as a mechanism to provide housing delivery support to the government, yet safeguard the interests of the private sector as well.

\section{Limitations of the study}

The study was meant to explore the scenario of housing and other building sectors PPPs in the EU. However, little empirical evidence was found due to strict confidentiality and gaining access to quantitative data about PPP projects making it a constant struggle. Therefore, to enable a thorough investigation, a semi-structured survey and interview questionnaire was designed giving the flexibility to the respondents to provide additional information in open inquiries. Notably, a lower rate of response from the private sector in the surveys further highlighted a lack of willingness to share details and contribute to the study. Such a study requires the industry to be more transparent and actively engage with the research initiatives in this field to ensure a comprehensive development and expansion of the PPP spectrum. Also, to keep the anonymity intact and respect the confidentiality agreement with the participants of surveys and interviews, their profiles could only be described in a restricted manner.

\section{Future outlook}

This paper is a part of overall research on performance review of PPPs and their application potential in housing. Future research tasks involve a series of publications focusing on country-specific case studies, identifying the key barriers, gaps, and challenges in five aspects vis-à-vis structural, contextual, organisational, environmental, and financial, and providing recommendations towards PPP in housing. Together, this shall provide a holistic view of results in this direction.

Acknowledgements The author would like to thank Prof. Sacha Menz and Prof. Dr. Bryan T. Adey for their consistent support and guidance during this research. The author would also like to thank all the participants of the survey and interviews for facilitating the data required for this research.

Funding This research did not receive any specific grant from funding agencies in the public, commercial, or not-for-profit sectors. Funding for open access publishing was provided by Bauhaus-Universität Weimar (3087).

\section{Compliance with ethical standards}

Conflict of interest The author declares there is no conflict of interest.

Open Access This article is licensed under a Creative Commons Attribution 4.0 International License, which permits use, sharing, adaptation, distribution and reproduction in any medium or format, as long as you give appropriate credit to the original author(s) and the source, provide a link to the Creative Commons licence, and indicate if changes were made. The images or other third party material in this article are included in the article's Creative Commons licence, unless indicated otherwise in a credit line to the material. If material is not included in the article's Creative Commons licence and your intended use is not 
permitted by statutory regulation or exceeds the permitted use, you will need to obtain permission directly from the copyright holder. To view a copy of this licence, visit http://creativecommons.org/licenses/by/4.0/.

\section{Appendix 1: Broad inquiries for surveys and interviews}

1. Describe your experience with Public-Private Partnerships, in general.

2. What characteristics would you generally associate with Public-Private Partnerships?

3. What has been the success rate of PPPs?

4. What type of building projects have you adopted the PPP approach for? Why was PPP chosen for these projects?

5. What type of contract models are mostly adopted in PPPs?

6. What are the key Critical Success Factors and Performance Indicators for PPPs?

7. What courses of action/ implementation measures are adopted in the Public-Private Partnerships you have been involved in?

8. What would you suggest as an apt bidding approach from your experience, suitable for Public-Private Partnerships in different sectors, for minimising project risks?

9. Which is the most common financing model for PPPs in general, and which can be best suited for housing PPPs?

10. Which measures or strategies are usually adopted for PPPs to counter an event of failure or uncertainty?

11. What level of compromises are generally made over factors of time, cost or quality in the Public-Private Partnerships you have been involved in?

12. What government tools, constrain or enable you to get involved in housing PPPs?

13. Which type of project/s would be best suitable for PPPs

14. How well a PPP project is accepted among the political and social communities?

15. How can abundant private sector's interest be generated for PPPs in housing?

16. Do you think PPP is an efficient way of delivering housing?

17. What measures can be taken to encourage collaboration between stakeholders?

\section{Appendix 2: Glossary of terms for survey graphs}

Access to private finance

Benefits to cost

Bidding processes

Budgeted expenditure

Capital market
This refers to the accessibility of private capital. It can enhance a firm's capital structure, save on costs, and improve managerial incentive alignment

Identify the relationship between the project cost and the benefits and summarise the overall value for money for a project

A PPP bidding process involves a series of stages: procurement and pre-qualification, an invitation to tender, interaction with bidders, and evaluation of tenders and contract award. The objective is to maximise the value for money

Estimating the incoming revenue and outgoing expenses over the life of a project

Available capital outside the banking system (For example: Bond financing) 
Capital value

Competitive negotiations

Competitive procurement/competitive bidding

\section{Contracting expertise}

Contractual terms

Cost

Critical success factors

Defined project objectives

Detailed and descriptive contract

Direct negotiations

Disputes

Economic feasibility

Faster delivery

Financial institutions leading in transactions

Financial viability

Flexibility

Government Control
The market value of long-term investment or asset such as land

Competitive negotiations allow for one-to-one discussions between the procurer and the individual bidders. RFPs are sent only to qualified bidders in competitive negotiations. Independent negotiations are then carried out with each bidder falling under the predetermined competitive range

The competitive dialogue involves a dialogue phase before the tender stage, where the public partner and the prospective bidders can discuss and negotiate all concerns of the contracts including finances. However, the same is not permitted in a tender stage and only technical and specifications-based clarifications can be sought during the tender phase

The level of expertise in the development of project procurement and contracting strategy to manage projects ranging from large-scale, complex capital developments to smaller-scale projects

The terms or provisions forming part of a contract. The contractual terms give rise to the contractual obligations, breach of which can give rise to litigation

A detailed, time-phased estimate of all resource costs for a project

Factors that define the critical tasks or activities that must be completed to a high standard of quality to achieve the project goals. CSFs help prioritise the tasks while the project plan is being executed

Defined objectives that describe the specific, tangible or intangible deliverables that the project shall deliver

Refers to the level of detailed specifications in the contract conveying the requirements of a project

Direct negotiations involve negotiating directly with a private firm without undergoing a competitive process

Disagreements that may arise at any time in the PPP process, out of a situation or adverse effect and requires resolution

Feasibility of securing financing whether from the public, commercial or concessional sources

The propagated advantage of quick execution and delivery through a PPP procurement as compared to any alternative procurement route, often because of better risk-sharing and management, and performance-based payments system

The financial institutions/ investors lead the project in transactions

The ability to generate sufficient income to meet the operating payments, debt, commitments and allow for growth while maintaining service levels

The ability of the contract clauses to effectively respond to changing circumstances throughout the term of the contract, proactively anticipate and address the contingencies and their solutions

The level of control exercised by the government/ public sector in a PPP over the private partner or the SPV 
Government need

Government promotion

Government support

Innovation

Long-term contracts

Long-term maintenance budgeting

Monitoring and evaluation

Operating costs

Output specifications

Partnership trust and commitment

Payment mechanisms

Performance indicators

Performance-linked payments

Political consent

Pre-qualification exercise

Private sector efficiency

Private sector expertise

Profitability

Project control

Project monitoring

Public debt
Refers to the requirement of the government/ public partner for undergoing a partnership

Refers to publicising of the PPP project to increase public awareness

Refers to the direct, indirect or contingent support for the project from the government/public partner; for example, through subsidies/grants, equity investment or guarantees

Refers to the scope of innovation with respect to the output specifications, such as policy, financial, design or technical innovation

This refers to the long tenure of a PPP contract such as 25 years or more

LTM refers to the budget allocation for a work of a nonroutine nature that may be required where project elements have failed or are in danger of failing or no longer comply with the requirements

A process that helps improve the performance of the project and achieve results. Its goal is to improve current and future management of outputs, outcomes, and impact

The costs regarding the operation and maintenance of the facility or the service provided

This refers to the project requirements that are defined in terms of outputs rather than inputs

This refers to a commitment by the parties within a PPP contract to collaborate and maintain a trustworthy relationship to achieve mutual goals

Principal means for allocating risks and providing incentives in the PPP contract

Indicators are utilised to measure project success. They demonstrate how effectively the project objectives are being achieved

A form of payment from the public to the private partner, which is directly related to the performance output of the project and which is specified in the PPP contract

The committed support of the government and the current political parties to allow the smooth development of the PPP

Aims at pre-qualifying potential bidders for the project. It involves assessment of their technical and managerial competence and financial soundness

Refers to the efficiency to perform with utilising the minimal resources to achieve the project objectives

Refers to the skill and knowledge of the private partner for undertaking a PPP procurement

The degree to which the project yields profit or financial gains

Data gathering, management and analytical processes used to predict, understand and constructively influence the time and cost outcomes of a project

Regular observation and recording of activities and progress taking place in a project

Debt owed by the government/ public sector to lenders outside of itself. It also includes national debts 
Quality

Quality control

Re-negotiations

Resource efficiency

Return on investment (ROI)

Risk allocation and transfer

Risk management strategy

Scope changes

Single-stage bidding

Sound business case

Stakeholder consultations

Subsidy

Tendering process

Time

Transaction costs

Transparency
The level to which the project meets its specifications or meets the expectations of the users

Involves maintaining the quality of the project delivery per the standards laid down in the contract

Re-negotiations involve a change in the contractual conditions, which may or may not affect the project monetarily, as well as the project schedule. They are used as a tool to address the uncertainty of PPP projects and as a mechanism to restore its economic and financial equilibrium

Refers to utilising limited resources in a sustainable manner while minimising impacts on the environment. It allows to create more with less and to deliver greater value with less input

The benefit achieved by an investor by investing finance or resources in a PPP project

The ability to identify, analyse and allocate project risks adequately. Failure to do so can have financial implications and/or the failure of the project to achieve its objectives

A risk management strategy provides a structured and coherent approach to identifying, assessing and managing risk. It builds in a process for regularly updating and reviewing the assessment based on new developments or actions taken

An official decision made by either of the partners to change any terms in the contract. It involves making adjustments to the cost, budget, other features, or the timeline

Involves the submission of technical and financial bid together in one envelope

Well-Structured reasoning for initiating a project. It is used importantly for project selection and the evaluation of investment opportunities

A two-way process of dialogue between the stakeholders of a project, about achieving the objectives to the laid down standards, and initiating and sustaining constructive external relationships over time

A form of financial aid or support extended to a sector, generally to promote economic and social development

Making an offer, bid or proposal, or expressing interest in response to an invitation or request for tender, for the selection of the private partner

Schedule of a project involving efficient use of time through good organisation, efficient productivity, and proper planning and delivery

Transaction costs refer to all the upfront costs such as cost of bids preparation and execution, making and administering of the contract, re-negotiations, or costs concerning any deviations in the contract

The extent to which all the information about the project including its budgetary information, is made available for all the involved parties, the end-users, and the public. It focuses on the parameters of openness, communication, and accountability 
Two-stage bidding

Upfront costs

User involvement

User satisfaction

Value for money

Win-Win situation
Involves the submission of technical and financial proposals in two stages, one after the other

Expenses that are charged at the beginning of a contract or project

An active consultation and engagement of the end-users of the facility by the stakeholders in the planning, development and delivery process, ensuring complete transparency and spread of public awareness

The satisfaction of users of the PPP project against the delivered objectives

Net positive gain greater than, that through any alternative procurement route

This refers to the situation that is beneficial for each partner involved in a project

\section{References}

ACT Government. (2014). What is community housing?. Belconnen: ACT Government.

Adejumo, A. A. (2008). Some thoughts on affordable and social housing in Nigeria. Village square: Prototype buildings.

Akintoye, A., Taylor, C., \& Fitzergald, E. (1998). Risk analysis and management of private finance initiative projects. Engineering, Construction, Architecture Management, 5(1), 9-21.

Akitoby, B., Hemming, R., \& Schwartz, G. (2007). Public investment and public-private partnerships. Wahington: IMF Publications.

Amann, W. (2009). new policies to facilitate affordable housing in Central and Eastern Europe. Housing Finance International., 24, 24.

Amann, W., \& Mundt, A. (2005). The Austrian system of social housing finance. Vienna: IIBW.

APMG. (2016). Public-Private Partnership (PPP) Certification Guide. Buckinghamshire: PPIAF.

Asian Development Bank. (2008). Pacific private sector policy brief: Public-private partnerships. Sydney: ADB.

Athias, L., \& Saussier, S. (2007). Un partenariat public-prive rigide ou flixible? Theorie et applications aux concessions routieres. Revue Economique, 58, 565-576.

Badshah, A. (1998). Good Governance for Environmental Sustainability. New York: UNDP.

Bardeleben, K., \& Puggaard, H. (2012). PPP trends in Denmark. https://ijglobal.com/articles/81185/ppptrends-in-denmark\#article. Accessed 17 Jan 2020.

Beuve, J., de Brux, J., \& Saussier, S. (2014). Renegotiations, discretion and contract renewals: An empirical analysis of public-private agreements. Paris: Sorbonne Business School.

Bissett, J. (2008). Regeneration: Public good or private profit?. Dublin: TASC.

C\&AG. (2010). PFI in housing. London: The Stationary Office.

Carbonara, N., Costantino, N., \& Pellegrino, R. (2016). A transaction costs-based model to choose PPP procurement procedures. Engineering, Construction and Architectural Management, 23(4), 491-510.

Chan, A. P., Chan, D. W., \& Yeung, J. F. (2010). Relational contracting for construction excellence. New York: Spon Press.

Corner, D. (2006). The United Kingdom private finance initiative: The challenge of allocating risk. OECD Journal on Budgeting, 5(3), 44.

Davidson, N., \& Malloy, R. (2009). Affordable housing and public-private partnerships. New York: Ashgate.

Davies, P., \& Osmani, M. (2011). Low carbon housing refurbishment challenges and incentives: Architects' perspectives. Building and Environment, 46(8), 1691-1698.

Deeleman, F. (2013). PPP in Dutch government housing. The Hague: Ministerie van Binnenlandse Zaken en Koninkrijksrelaties.

Developments, P. (2013). Two study projects: Cedarbrook and Hannover Quay. Dublin: John Sisk and Sons. DOELG. (2000). Introduction to public-private partnerships. Dublin: Department of the Environment and Local Government. 
Donohue, J., \& Dorman, P. (2006). Dream/Dare/Do: A regeneration learning manual. Dublin: Fatima Groups United.

Dudkin, G., \& Välilä, T. (2005). Transaction costs in public-private partnerships: A first look at the evidence (pp. 307-330). EIB: Luxembourg.

EIB. (2004). The EIB's role in Public-Private Partnerships. Luxembourg: European Investment Bank.

EIB. (2008). Infrastructure investment, growth and cohesion. EIB (Papers ed.). Luxembourg: Economic and Financial Studies Division, European Investment Bank.

EIB. (2015). The EPEC PPP Guide. Luxembourg: European PPP Expertise Centre.

EPEC. (2015). Market update review of the european PPP Market in 2014. Luxembourg: EIB.

EIB. (2019). European PPP Expertise Centre-What is PPP.https://www.eib.org/epec/index.htm. Accessed Jan 25, 2019.

Eldrup, A., \& Schütze, P. (2013). Organization and financing of public infrastructure projects. Copenhagen: Offentligt-Privat Partnerskab.

Energy Efficient Buildings Association E2BA. (2013). EeB PPP Project Revie. Brussels: European Commission.

Engel, E., Fischer, R., \& Galetovic, A. (2011). Public-private partnerships to revamp US infrastructure. Washington DC: Brookings.

EPEC. (2016). Market Update Review of the European PPP Market in 2015. Luxembourg: EIB.

EPEC. (2017). Market update review of the European PPP Market in 2016. Luxembourg: EIB.

EPEC. (2018). Market update review of the European PPP Market in 2017. Luxembourg: EIB.

Ergas, H. (2009). Cronyism on the sly. Surry Hills: The Australian.

Eriksen, K. S., et al. (2007). Evaluering av OPS $i$ vegsektoren. Oslo: Transportøkonomisk Institutt.

Estache, A., \& Saussier, S. (2014). Public private partnerships and efficiency: A short assessment. Paris: Chaire Economie des Partenariats.

Eurostat. (2017). Housing Statistics.https://ec.europa.eu/eurostat/statistics-explained/index.php/Housing_ statistics. Accessed Apr 07, 2017

Farajian, M., \& Cui, Q. (2010). Transaction cost in public-private partnerships. Maryland: Semantic Scholar.

Finnerty, J. D. (1996). Project financing: Asset-based financial engineering. New York: John Wiley and Sons.

Flanagan and Norman. (1999). Risk management and construction. Oxford: Blackwell.

Gausch, J. L. (2004). Granting and renegotiating infrastructure concession: Doing it right. Washington DC: World Bank.

Gill, P., Stewart, K., Treasure, E., \& Chadwick, B. (2008). Methods of data collection in qualitative research: Interviews and focus groups. British Dental Journal, 204, 291-295.

Grimsey, D., \& Lewis, M. K. (2005). The economics of public-private partnerships. The International Library of Critical Writings in Economics. Cheltenham: Edward Elgar.

Gul, M. S., \& Menzies, G. F. (2012). Designing domestic buildings for future summers: Attitudes and opinions of building professionals. Energy Policy, 45, 752-761.

Hardcastle, C., Edwards, P. J., Akintoye, A., \& Li, B. (2005). Critical success factors for PPP/PFI projects in the UK construction industry: A factory analysis approach (pp. 75-83). Hong Kong: The University of Hong Kong and Hong Kong Institution of Engineers.

Herpen, G. (2002). Public-private partnerships The Advantages and Disadvantages Examined. New York: Association for European Transport.

Huey-Tsyh, C. (1996). Epilogue: Synthesizing formative/summative evaluation issues and beyond. Evaluation Practice, 17(2), 163-167.

Ihuah, P. W., Kakulu, I. I., \& Eaton, D. (2014). A review of critical project management success factors (CPMSF) for sustainable social housing in Nigeria. International Journal of Sustainable Built Environment, 3, 62-71.

International Financial Services London, IFSL. (2004). Public private partnerships UK Case Studies. London: IFSL.

Kappeler, A., \& Nemoz, M. (2010). Public-private partnerships in Europe-before and during the recent financial crisis. Luxembourg: EIB.

Krueger, R. A. (1994). Focus groups: A practical guide for applied research. 2nd (edition ed.). Newbury Park: SAGE.

Li, B., Akintoye, A., Edwards, P. J., \& Hardcastle, C. (2005). Critical success factors for PPP/PFI projects in the UK construction industry. Construction Management Economics, 23(5), 459-471.

Li, B., Akintoye, A., \& Hardcastle, C. (2000). Conceptual framework for construction PPPs (pp. 229-240). Glasgow: Caledonian University, Association of Researchers in Construction Management. 
Li, H., Arditi, D., \& Wang, Z. (2013). Factors that affect transaction costs in construction projects. Journal of Construction Engineering and Management, 139(1), 60-68.

Lu, Y. C., Wu, S., Chen, D. S., \& Lin, Y. Y. (2000). BOT projects in Taiwan: Financial modeling risk, term structure of net cash flows, and project at risk analysis. Journal of Project Finance, 5(4), 53-63.

MacDonald, M. (2002). Review of large public procurement in the UK. UK: HM Treasury.

Matos-Castano, J., Dewulf, G., \& Mahalingam, A. (2012). The complex interplay between the institutional context and PPP project outcomes. EPOS: Rheden.

Meehan, T., Vermeer, C., \& Windsor, C. (2000). Patients' perceptions of seclusion: A qualitative investigation. Journal of Advanced Nursing, 31(2), 370-377.

Moskalyk, A. (2011). Public-Private Partnerships in Housing and Urban Development. In X. Q. Zhang \& E. Orina (Eds.), The Global Urban Economic Dialogue Series. UN-HABITAT: Nairobi.

NAO. (2007). Improving the PFI tender process. London: The Stationary Office.

NA Office NAO. (2009). Private finance projects: A paper for the Lords Economic Affairs Committee. UK: NAO.

NDFA. (2018). Schools PPP Bundle 4.https://www.ndfa.ie/project/schools-ppp-bundle-4. Accessed Feb 11, 2019.

Organisation for Economic Co-operation and Development, OECD. (2012). Recommendation of the council on principles for public governance of public-private partnerships. Paris: OECD Publishing.

Osei-Kyei, R., \& Chan, A. P. (2015). Review of studies on the critical success factors for public-private partnership (PPP) projects from 1990 to 2013. International Journal of Project Management., 33(6), 1335-1346.

PwC and ULI. (2019). Emerging trends in Real Estate: Creating an Impact. London: ULI.

PwC. (2005). Delivering the PPP promise: A review of PPP issues and activity. London: PricewaterhouseCoopers.

Richardson, L. (1995). Narrative and sociology. In J. Van Maanen (Ed.), Representation in ethnography (pp. 198-221). Thousand Oaks: SAGE Publications.

Riessman, C. K. (2008). Narrative methods for the human sciences. Thousand Oaks: SAGE Publications.

Roehrich, J. K., Lewis, M. A., \& George, G. (2014). Are public-private partnerships a healthy option? A systematic literature review. Social Science and Medicine, 113, 110-119.

Savas, E. S. (2000). Privatization and public-private partnerships. New York: Chatham House Publishers.

Scanlon, K., \& Whitehead, C. (2008). Social Housing in Europe II. London: LSE London.

Service Works Global. (2015). Public private partnerships: What the world can learn from Canada. London: SWG.

Soliño, A. S., \& de Santos, P. G. (2016). Influence of the tendering mechanism in the performance of public-private partnerships: A transaction cost approach. Public Performance and Mangement Review, $40(1), 91-118$.

Stonehouse, J. H., Hudson, A. R., \& Okeefe, M. J. (1996). Priavte-public partnerships: The toronto hospital experience. Canadian Business Review, 23(2), 17-21.

Sykorovà, L. (2013). Comparison of PPP Practice in Four European Countries. Prague: CTU.

Tony, G. (1996). Key to successful public-private partnerships. Canadian Business Review, 23(3), 27-28.

Treasury, H. M. (2012). A new approach to public-private partnerships. London: The Stationary Office.

UN-Habitat. (2011). Public-private partnerships in housing and urban development. Nairobi: UN-Habitat.

URBACT. (2016). EU Urban Agenda: The challenge of "affordable housing" in Europe. https://ec.europ a.eu/futurium/en/housing/eu-urban-agenda-challenge-affordable-housing-europe-laura-colini-urbac t-expert. Accessed 20 Jan 2020

US Department of Transportation, DOT. (2004). U.S Department of Transportation.https://www.transporta tion.gov/.

Dot, U. S. (2012). Value for money assessment for public-private partnerships: A primer. Washington DC: Federal Highway Administration.

World Bank (2014). Public-private infrastructure advisory facility.https://www.ppiaf.org/node/89. Accessed Oct 14, 2018.

World Bank Group (2016). Project Finance-Key Concepts.https://ppp.worldbank.org/public-private-partn ership/financing/project-finance-concepts. Accessed Oct 24, 2017.

World Bank, ADB and IADB. (2014). Public-private partnerships reference guide. Washington: World Bank Publications.

World Bank Group. (2019). Government support in financing PPPs.https://ppp.worldbank.org/public-priva te-partnership/financing/government-support-subsidies. Accessed Sep 13, 2019.

Publisher's Note Springer Nature remains neutral with regard to jurisdictional claims in published maps and institutional affiliations. 